\title{
The genome and transcriptome of the enteric parasite Entamoeba invadens, a model for encystation
}

\author{
Gretchen M Ehrenkaufer ${ }^{1 \dagger}$, Gareth D Weedall ${ }^{2 \dagger}$, Daryl Williams ${ }^{2}$, Hernan A Lorenzi ${ }^{3}$, Elisabet Caler ${ }^{3}$, Neil Hall ${ }^{2,4^{*}+}$ \\ and Upinder Singh ${ }^{1,5^{*}+}$
}

\begin{abstract}
Background: Several eukaryotic parasites form cysts that transmit infection. The process is found in diverse organisms such as Toxoplasma, Giardia, and nematodes. In Entamoeba histolytica this process cannot be induced in vitro, making it difficult to study. In Entamoeba invadens, stage conversion can be induced, but its utility as a model system to study developmental biology has been limited by a lack of genomic resources. We carried out genome and transcriptome sequencing of E. invadens to identify molecular processes involved in stage conversion.

Results: We report the sequencing and assembly of the E. invadens genome and use whole transcriptome sequencing to characterize changes in gene expression during encystation and excystation. The E. invadens genome is larger than that of E. histolytica, apparently largely due to expansion of intergenic regions; overall gene number and the machinery for gene regulation are conserved between the species. Over half the genes are regulated during the switch between morphological forms and a key signaling molecule, phospholipase D, appears to regulate encystation. We provide evidence for the occurrence of meiosis during encystation, suggesting that stage conversion may play a key role in recombination between strains.

Conclusions: Our analysis demonstrates that a number of core processes are common to encystation between distantly related parasites, including meiosis, lipid signaling and RNA modification. These data provide a foundation for understanding the developmental cascade in the important human pathogen E. histolytica and highlight conserved processes more widely relevant in enteric pathogens.
\end{abstract}

\section{Background}

Conversion between distinct developmental stages is an essential part of the life cycle of many pathogens and is necessary for transmission. For enteric protozoa, the transmissible stage is the cyst, which allows survival outside of the host [1]. Understanding the molecular processes controlling stage conversion is central to the development of transmission-blocking therapies as well as novel diagnostics [2,3]. Entamoeba histolytica causes colitis and dysentery and infects 500 million people per

\footnotetext{
* Correspondence: neilhall@liv.ac.uk; usingh@stanford.edu

+ Contributed equally

'Division of Infectious Diseases, Department of Internal Medicine, Stanford University, Stanford, California, 94305, USA

${ }^{2}$ Institute of Integrative Biology, University of Liverpool, Crown Street,

Liverpool, UK

Full list of author information is available at the end of the article
}

year worldwide [4]. The related Entamoeba invadens causes a similar invasive disease in reptiles [5]. The Entamoeba life cycle has two stages: trophozoites, which proliferate in the colon and cause disease, and nondividing, multinucleate cysts that are transmitted to new hosts [6].

Research into the molecular basis of conversion between these two forms has been hampered by the absence of tools to induce encystation and excystation in in vitro axenic cultures of E. histolytica $[7,8]$. Clinical $E$. histolytica isolates maintained in xenic culture are capable of stage interconversion and have been used to examine the transcriptome of E. histolytica cysts [9]. However, the percentage of cells forming cysts is low and stage conversion is asynchronous [10]. While interesting developmentally regulated genes were identified, the inability to isolate cysts at different developmental 
stages likely prevented the discovery of many important regulators of encystation.

Due to the lack of in vitro methods for studying encystation in E. histolytica, the reptile parasite E. invadens has been utilized as a model system to study development. The IP-1 strain was originally isolated from a natural infection of a painted turtle, Chrysemys picta, and is pathogenic in snakes [5]. E. invadens IP-1 can form cysts in axenic culture and methods have been developed to induce high efficiency encystation and excystation in vitro $[6,11]$. Using this system, many features of cyst wall biosynthesis have been elucidated [12,13] and several compounds that enhance or inhibit encystation have been identified, including protein kinase $C$ inhibitors and cytochalasins [14-16], suggesting that these pathways may be involved in regulating development. Recently, genetic tools have been developed to allow stable protein expression in E. invadens $[17,18]$, further enhancing its usefulness as a model system.

Genome-wide transcriptional profiling using microarrays has been an important tool for increasing our understanding of parasite stage conversion [19-21]. Recent advances in high-throughput sequencing have allowed development of RNA-Sequencing (RNA-Seq), in which an entire transcriptome (reviewed in [22]) is sequenced and relative expression of each transcript deduced from read frequencies. In this paper we present the genome assembly and annotation of E. invadens IP-1, RNA-Seq analysis of transcriptional changes during the complete developmental cycle (encystation and excystation), and the functional demonstration that perturbation of the phospholipase D (PLD) pathway inhibits stage conversion in Entamoeba. Our findings demonstrate major changes in gene expression during encystation and excystation in Entamoeba, and provide insight into the pathways regulating these processes. A better understanding of processes regulating stage conversion may guide targeted interventions to disrupt transmission.

\section{Results and discussion}

\section{The $E$. invadens genome assembly and predicted gene models}

In order to determine the genome sequence of $E$. invadens, 160,419 paired-end Sanger sequenced reads derived from E. invadens genomic DNA were assembled [23]. A small number of contigs were removed due to small size and possible contamination, and a total of 4,967 contigs in 1,144 scaffolds were submitted to GenBank under the accession number [AANW00000000] (Bioproject PID PRJNA12926). The total scaffold span (including estimated gap sizes) was $40,878,307$ bp $(40,496,007$ bp excluding gaps). The average intra-scaffold gap size was estimated to be 660 bases (however, all gaps were represented by 100 'N's in the final assembly). Over $50 \%$ of the assembly is represented in scaffolds larger than 231,671 bases and contigs larger than 17,796 bases. The total assembly size was nearly twice that of $E$. histolytica (approximately $22 \mathrm{MB}$ ). The nucleotide composition (35\% A, 35\% T, 15\% G, $15 \% \mathrm{C}$ ) was slightly less A+T-rich than E. histolytica $(70 \%$ versus $75 \% \mathrm{~A}+\mathrm{T})$. Automated gene prediction and manual curation defined 11,549 putative protein coding genes analyzed in this study (the number of genes in the GenBank genome was higher at 11,997 , due to genes containing gaps being split into two or more genes). The predicted protein length distribution is shown in Figure 1a. Of these gene models, $35 \%$ were predicted to contain one or more intron (Table 1).

Of the 11,549 predicted $E$. invadens genes, 9,865 have a BLASTP (E-value $<10^{-5}$ ) hit to an E. histolytica gene (7,216 of the 8,306 predicted genes in E. histolytica had a BLASTP hit to an E. invadens gene) and 5,227 genes were putative orthologs (reciprocal best BLAST hits). Average amino acid identity between aligned regions of orthologs is $69 \%$, suggesting that the species are distantly related (similar in distance to Plasmodium falciparum and Plasmodium vivax, for example). Of the E. invadens genes without orthologs in E. histolytica, $77 \%(4,815 / 6,218)$ have at least some RNA-Seq support, compared to $98 \%(5,206 / 5,331)$ of genes shared with E. histolytica. This result could suggest that a proportion of these genes are false positive predictions; however, it is also consistent with these being contingency genes that are not constitutively expressed so transcripts are less likely to be detected.

To identify the level of conserved synteny between the two species, we identified all collinear gene pairs that were adjacent in both E. histolytica and E. invadens. Only 561 genes maintained their neighboring gene in both species (out of a total of 5,227 ). Hence, it appears that there has been extensive genomic rearrangement between these species.

Both E. histolytica and E. invadens genomes are highly repetitive and only around $50 \%$ of the genome size, in both species, is accounted for by genic and intergenic sequence due to the large number of contigs that are unscaffolded and do not contain annotation. The larger genome size of E. invadens cannot be accounted for simply by the greater number of predicted genes: 11,549 in E. invadens compared to 8,306 in E. histolytica. We compared the length distributions of genes and intergenic sequence in the two genomes; Figure 1 shows the distribution of gene and intergenic sizes in the two species. It is clear from these analyses that the gene lengths of $E$. histolytica and $E$. invadens are very similar whereas the intergenic regions in $E$. invadens tend to be longer than those in E. histolytica. A previous analysis of transposons and retrotransposons in E. invadens [24] suggests that repetitive elements are not more common in E. invadens. Thus, 


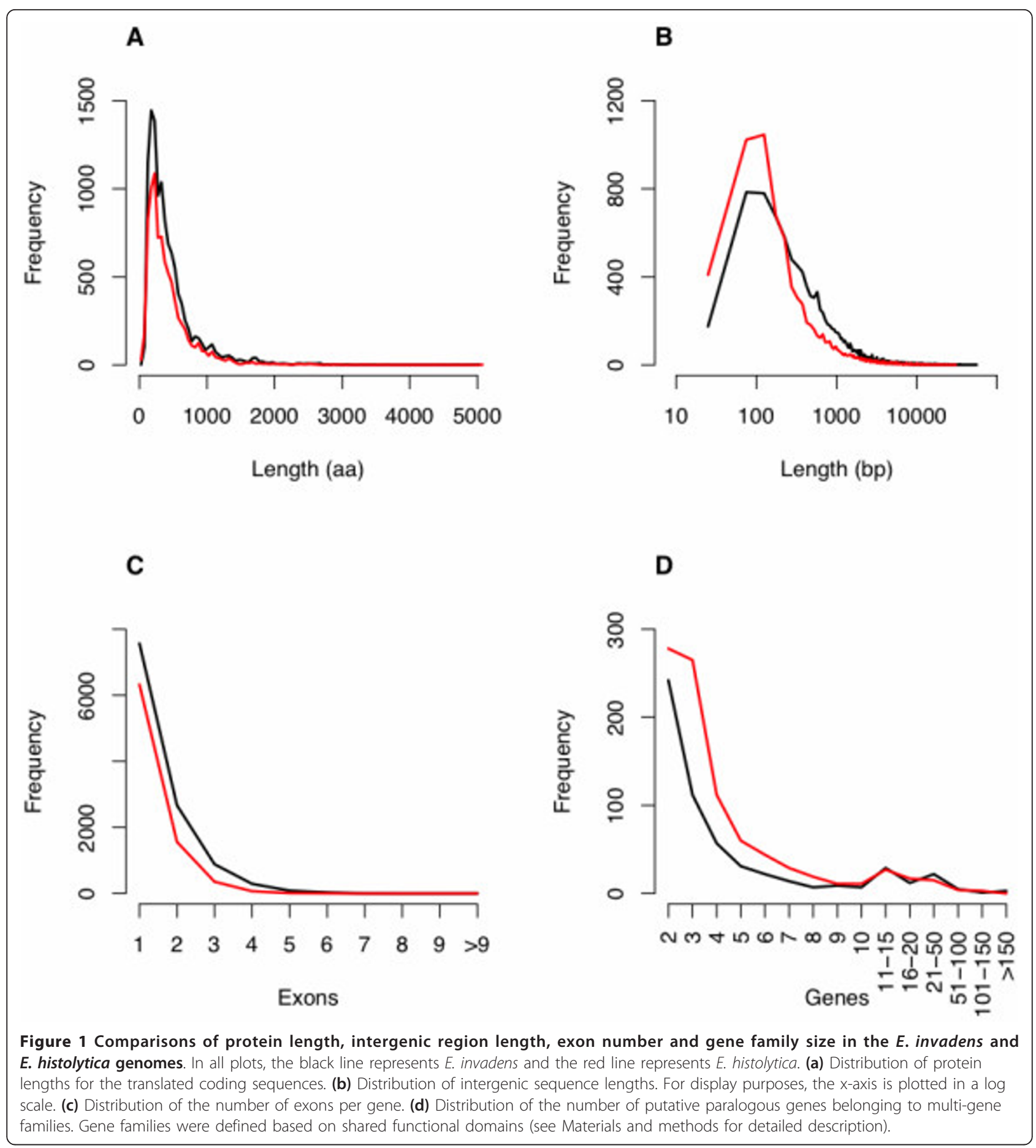

the longer intergenic regions are unlikely to have increased in size due to transposon/retrotransposon activity, as the previous analysis failed to identify many E. invadensspecific repeat elements. However, one possibility is that differences in annotation and the lower depth of coverage in E. invadens resulted in an under-calling of genes, thus making intergenic regions appear larger in $E$. invadens. To check this, we compared the sizes of the intergenic spaces between the 561 pairs of colinear orthologous genes identified in the syntenic analysis. This revealed that the mean intergenic distance between gene pairs in E. invadens is $408 \mathrm{bp}$ while it is only $282 \mathrm{bp}$ in E. histolytica. In both $E$. histolytica and $E$. invadens the mean distance between genes where they were divergently transcribed (550 bp and $341 \mathrm{bp}$ ) was on average, considerably larger than the distance between genes that were transcribed toward each 
Table 1 Introns detected by whole transcriptome mapping

\begin{tabular}{|c|c|c|c|c|c|}
\hline Sample & Introns & Confirm annotation (\%) $^{\mathrm{a}}$ & Match $5^{\prime}$ & Match 3' & Novel \\
\hline Trophozoite & 1,628 & $1,345(23 \%)$ & 19 & 11 & 253 \\
\hline Cyst_8h & 2,163 & $1,771(30 \%)$ & 23 & 10 & 359 \\
\hline Cyst_24h & 1,955 & $1,536(26 \%)$ & 21 & 12 & 386 \\
\hline Cyst_48h & 1,047 & $811(14 \%)$ & 15 & 5 & 216 \\
\hline Cyst_72h & 1,272 & $1,027(17 \%)$ & 9 & 6 & 230 \\
\hline Excyst_2h & 1,438 & $1,229(21 \%)$ & 12 & 6 & 191 \\
\hline Excyst_8h & 764 & $666(11 \%)$ & 5 & 2 & 91 \\
\hline All & 3,239 & $2,470(42 \%)$ & 35 & 17 & 717 \\
\hline
\end{tabular}

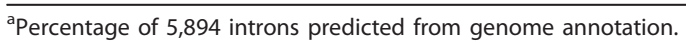

other (284 bp and188 bp), presumably because in both species the 5' regions were required for transcription factor binding. Considered together, these observations suggest an expansion of the intergenic regions in E. invadens relative to $E$. histolytica, possibly as a result of differential strengths of selection on intergenic sequence size - for example, weaker selection against expansion in $E$. invadens may allow intergenic regions to expand through genetic drift. However, in some fungal plant pathogens genome expansion has been associated with adaptation to different hosts [25], as gene family expansion and repeat driven chromosomal rearrangement can accelerate genomic diversity. As E. invadens infects a broad range of hosts, including lizards, snakes and turtles, while E. histolytica is primarily associated with humans and primates, it is possible that the observed difference in genome size reflects this discrepancy of host range restriction.

The genome of E. histolytica is highly repetitive, with many genes occurring in large multi-gene families [24]. This is also the case in E. invadens. Predicted proteins were clustered into putative gene families based on possession of shared domains (see Materials and methods section and Additional file 1 for description). There were 572 families of 2 or more genes and 78 families of 10 or more genes. The distribution of gene family sizes is shown in Figure 1d and 1all genes assigned to multigene families are shown in Additional file 2. The predicted functions of the largest gene families highlight the importance of motility and signaling in the organism's survival. The largest gene families include two families of protein kinases $(n=410$ and $n=135)$, phosphatases $(n=74)$, small GTP-binding proteins $(n=225)$, Rho-GTPases $(n=84)$, Rho/Rac guanine nucleotide exchange factors $(n=41)$, calcium-binding proteins $(n=70)$, WD-repeat-containing proteins $(n=61)$, actins $(n=53)$ and RNA-binding proteins $(n=48)$.

In addition to these well characterized gene families, the E. invadens genome contains representatives of gene families recently identified as having important biological roles in E. histolytica, including RNA interference pathway genes and Myb domain-containing transcription factors [26-29]. RNA interference (RNAi) is an important mechanism for gene regulation that has been found in the majority of eukaryotes studied [30]. Recently, the existence of an active RNAi pathway has been demonstrated in E. histolytica and found to be involved in gene silencing and strain-specific gene expression patterns [26,31,32]. In E. histolytica, small RNAs map to a subset of genes that are not expressed in trophozoites but are expressed in cysts [31], suggesting that RNAi could help regulate development in Entamoeba. Argonaute, a vital member of the RNA-induced silencing complex [33], is characterized by two conserved domains: the PAZ domain, which enables binding of small RNAs, and the PIWI domain, which is thought to be important for RNA cleavage. Examination of the E. invadens genome indicated the presence of two full-length Argonaute proteins (EIN_033570 and EIN_035430), a single PAZ domain protein (EIN_182430) and a PIWI domain protein (EIN_182370). Additionally, the E. invadens genome contains genes encoding RNA-dependent RNA polymerase (EIN_181590 and EIN_092660), thought to be required for the formation of small RNAs, and a single RNAseIII domain-containing gene (EIN_108010). The presence of these RNAi pathway genes in E. invadens suggests that an endogenous small RNA pathway may also regulate gene expression in E. invadens.

Myb family transcription factors are important regulators of gene expression. Although originally identified in mammals, where they play important roles in cell proliferation and differentiation [34], Myb domain-containing proteins have subsequently been identified in diverse species $[35,36]$, and they are the largest family of transcription factors in E. histolytica [37]. E. histolytica Myb domain-containing proteins have been implicated in development [29] and in the response to oxidative stress [27]. Myb proteins have also been shown to be regulated during colonic invasion [38] and liver abscess formation [39], indicating that these proteins are important in multiple aspects of amebic biology, and suggesting that this genus-specific expansion is required for Entamoebaspecific functions. We identified 44 Myb domaincontaining proteins in the E. invadens genome, including 
9 that contain a conserved SHAQKY motif (EIN_053790, EIN_054250, EIN_059020, EIN_134750, EIN_241140, EIN_020200, EIN_277760, EIN_015270, EIN_051670), indicating they are members of a sub-family of Myb proteins. This family is common in plants [40] and is found in Dictyostelium, where a SHAQKY domain protein was shown to regulate pre-stalk cell genes [41]. Further investigation will be required to elucidate potential roles for these proteins in biological processes of Entamoeba such as stage conversion.

Despite the different size of the $E$. invadens genome, our analysis suggests that it is very similar to E. histolytica in its core gene content. Although there has been lineagespecific expansion of intergenic regions and some gene families, the large family of Myb transcription factors and the machinery for RNAi has been conserved, suggesting that E. invadens is a good model for expression analysis.

\section{Whole transcriptome mapping to the $E$. invadens genome assembly}

In order to understand changes in gene regulation during E. invadens stage conversion and to assess the genome annotation, the transcriptomes of encysting and excysting parasites were sequenced. E. invadens trophozoites were induced to encyst by incubation in $47 \%$ low glucose media [42], and RNA was generated from $0 \mathrm{~h}, 8 \mathrm{~h}, 24 \mathrm{~h}, 48 \mathrm{~h}$, and $72 \mathrm{~h}$ time points (with the $72 \mathrm{~h}$ time point representing mature cysts). The experimental design is outlined in Figure 2. Samples from excysting parasites were generated by harvesting mature cysts ( $72 \mathrm{~h}$ after induction of encystation), incubating overnight in distilled water to eliminate any remaining trophozoites, and transferring to excystation medium [11] for $2 \mathrm{~h}$ or $8 \mathrm{~h}$. Only samples with high encystation or excystation efficiencies ( $>80 \%$ encystation assayed at $72 \mathrm{~h}$ or $>60 \%$ excystation assayed at $24 \mathrm{~h}$ ) were used for RNA analysis.

For each time point during encystation and excystation, short read sequencing libraries were generated from cDNA from two independent biological replicates. Libraries were sequenced on a SOLiD ${ }^{\mathrm{TM}} 4$ sequencer, and aligned to the E. invadens genome assembly [43]. Mapping statistics (Additional file 3) revealed that the proportion of sequences that aligned to the reference genome was comparable to published data [44]. The unmapped proportion of each library was only partially $(<5 \%)$ accounted for by tRNA gene arrays or rDNA genes, which are not represented in the genome assembly. Overall, reads that mapped to the genome were of high quality ( $>30$ phred score for all samples tested), giving further confidence that the mappings are valid. The correlation between biological replicates at each encystation and excystation time point (read counts per gene are shown in Additional file 4, read count correlations are shown in Additional file 5) revealed that replicates correlated to a reasonable degree, although some disparities were identified. Given that the encystation process is asynchronous, stochastic biological variation likely accounts for the differences. This variation among samples will make it difficult to identify subtle changes in gene expression but differential expression of more highly regulated genes can still be identified, given statistical significance [45], and provide important biological insights.

\section{Assessment of the accuracy of predicted $E$. invadens gene models using transcriptome data}

Mapping of RNA-Seq reads identified many unannotated transcribed regions of the genome. Many of these may be transcribed transposable elements but some may represent unannotated protein coding genes. In order to detect these, we mapped the transcriptome data to the genome using Tophat v1.3.2 [46], determined putative transcripts using Cufflinks and selected those that did not overlap an annotated gene. We then translated their sequences and used these to search for functional protein domains in the Pfam database [47]. The results are shown in Additional file 6. Common domains included DDE_1 transposases that are associated with DNA transposons, and hsp70 domains. In general, unannotated transcripts did not contain a single long open reading frame, indicating that genes were not predicted due to being pseudogenes or artifacts of low sequence coverage of the genome assembly. Overall, we did not find evidence of numerous long un-annotated open reading frames that had been missed by automated gene prediction.

To assess the accuracy of the genome annotation, we used the transcriptome data (mapped with Tophat v1.3.2 [46]) to identify introns. Overall, the alignment identified 3,239 putative introns; 2,470 of these were among the 5,894 predicted by computational gene calling (Additional file 7). A further 52 matched a predicted intron at only the 5' (35) or 3' (17) end, indicating a small number of misannotated introns (example in Figure 3c). A proportion of the 3,424 non-confirmed introns may be annotation errors, as suggested by a difference between the 5' consensus sequence of confirmed and non-confirmed introns (Figure 3a). Confirmed introns show an extended 5' consensus sequence (GTTTGT) compared to only the GT in unconfirmed introns, a pattern also seen in E. histolytica introns $[48,49]$. Other non-confirmed introns contained sequencing gaps (' $\mathrm{N}$ ' bases in the scaffold sequence), which might cause artifacts (introns that span a gap to make an intact gene model) in computational gene calling. Although these only accounted for $13.6 \%(464 / 3,424)$ of the non-confirmed introns, this proportion was much higher than the $0.1 \%(2 / 2,470)$ of confirmed introns that had sequencing gaps. To determine where the transcriptome data contradicted a predicted intron, we counted the number of $35 \mathrm{bp}$ reads that mapped entirely within each 


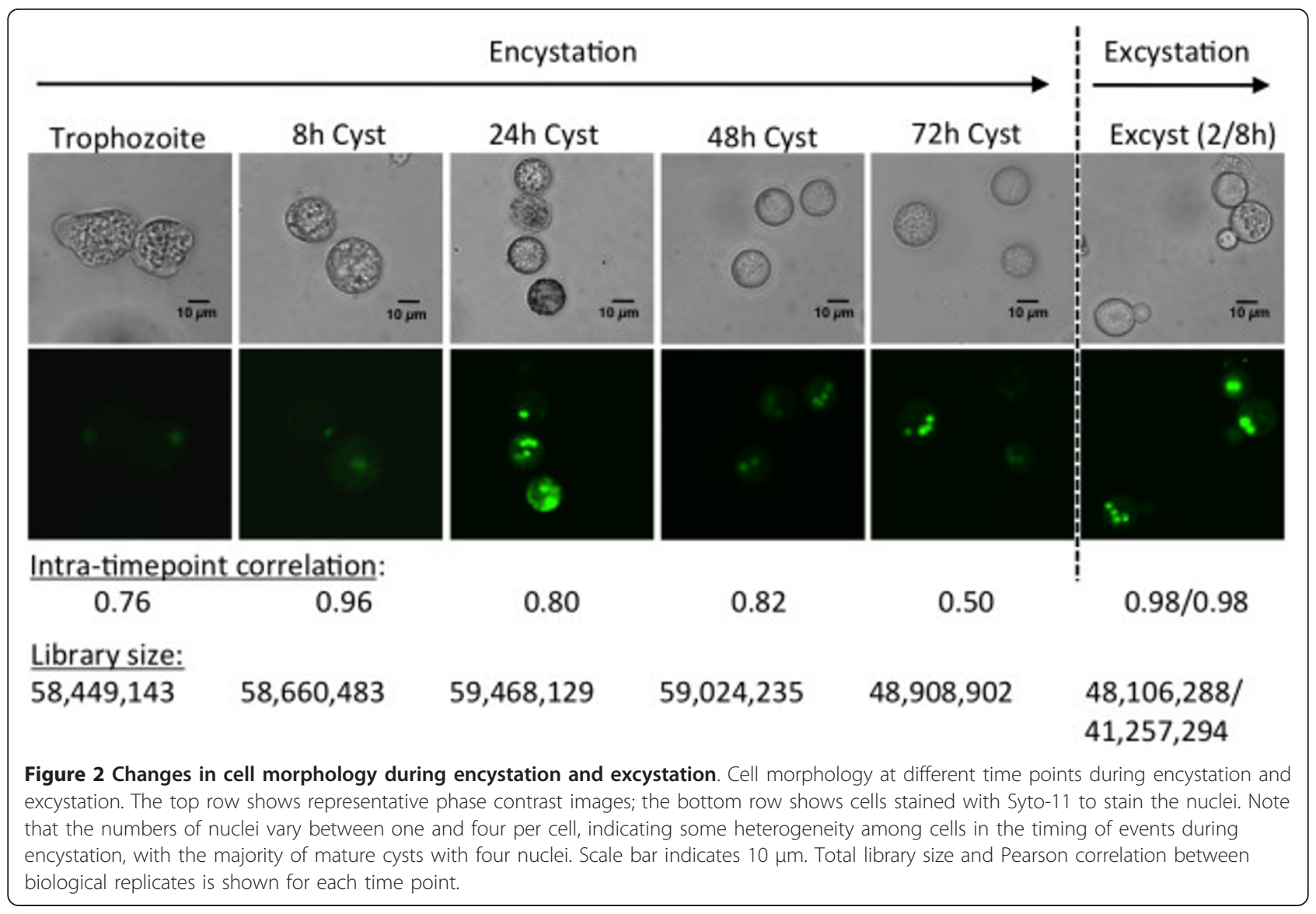

predicted intron. Overall, 308 predicted but nonconfirmed introns had more than five reads (from all libraries combined) aligned in the predicted intron (example shown in Figure 3b). However, we also identified 276 cases in which an intron was both confirmed and had $>5$ reads mapped within it. Whether this indicates intron retention in the transcripts, antisense transcripts, or lowlevel genomic DNA contamination is uncertain. Therefore, we could not use this to reject a predicted intron. In a small number of cases, the intron changed the reading frame of the gene model, or appeared to differ among libraries. This could be due to alternative splicing, or could be a reflection of stochastic noise, as recently observed in E. histolytica [49]. Overall, the transcriptome data provide empirical evidence confirming approximately $42 \%$ of the predicted introns in the genome.

\section{Changes in gene expression during encystation and excystation}

To explore transcriptional changes during encystation and excystation we estimated gene expression levels of the 11,549 putative protein coding genes at time points during encystation $(0 \mathrm{~h}, 8 \mathrm{~h}, 24 \mathrm{~h}, 48 \mathrm{~h}$ and 72 hours after induction of encystation) and excystation ( $2 \mathrm{~h}$ and
$8 \mathrm{~h}$ after induction of excystation). Normalized expression values for all genes were calculated (as fragments per kilobase of transcript per million mapped fragments (FPKM)) using Cufflinks v1.3.2 [46] (all shown in Additional file 4). The majority of genes (87\%; 9,992/11,549) were expressed at at least one time point, with between $55 \%$ (at $48 \mathrm{~h}$ encystation) and $78 \%$ (at $2 \mathrm{~h}$ excystation) expressed at any one time point. Expression levels were compared using two methods: (1) clustering genes by their temporal expression profile during encystation and excystation to gain a broad overview of transcriptional changes; (2) statistical pairwise comparisons of all time points to identify significantly up- and down-regulated genes.

We defined temporal profiles of gene expression during encystation $(0 \mathrm{~h}, 8 \mathrm{~h} 24 \mathrm{~h}, 48 \mathrm{~h}$ and 72 hours postencystation) and excystation (72 hour cysts, $2 \mathrm{~h}$ and $8 \mathrm{~h}$ post-excystation), for 4,577 and 5,375 genes expressed at all time points in each series, using the short time-series expression miner (STEM) program [50]. All temporal expression profiles are shown in Additional file 8, and genes belonging to each profile are tabulated in Additional file 4 . Nine clusters of related profiles contained significantly more genes than expected by chance during 


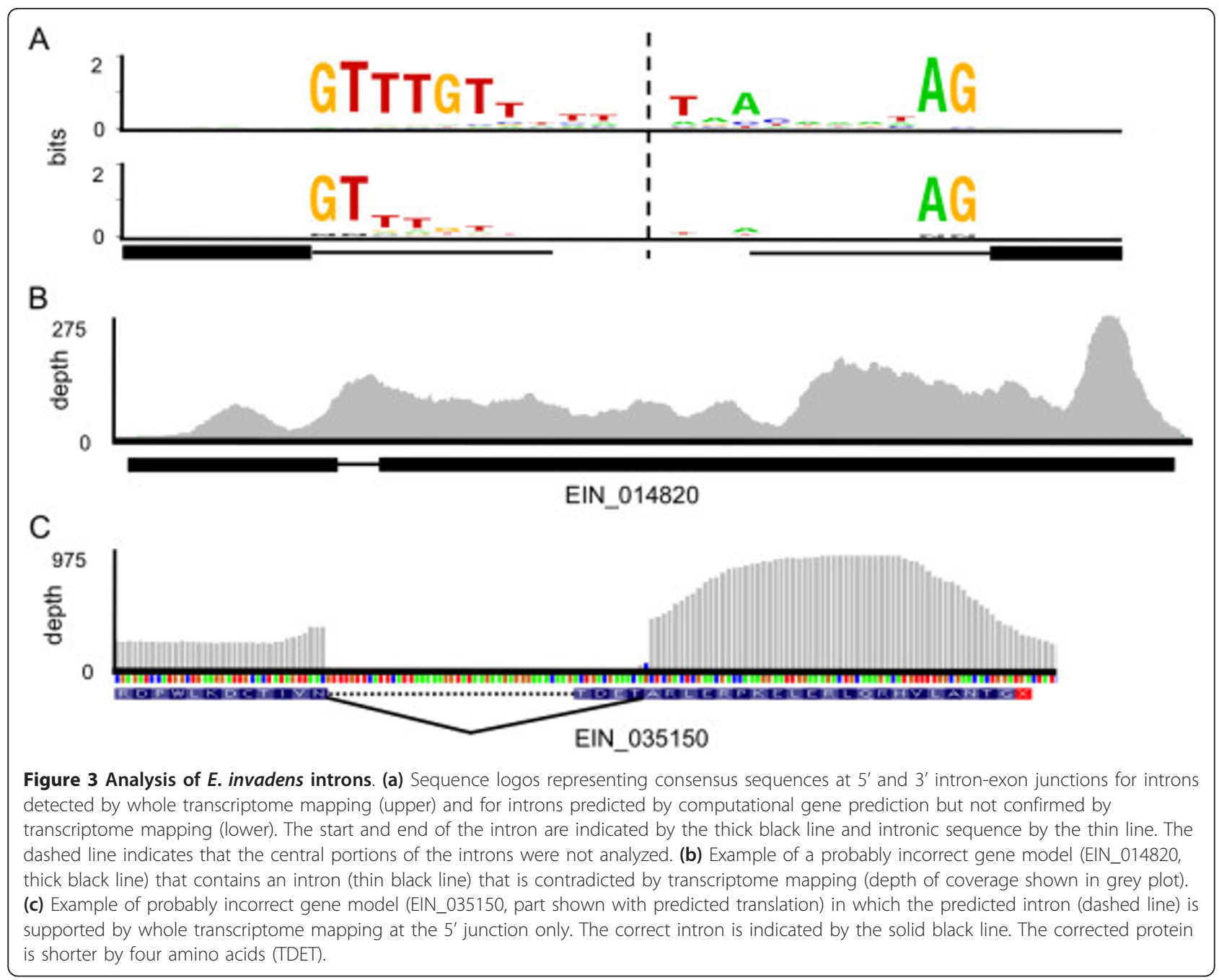

encystation and five similarly enriched clusters during excystation (Figure 4). During encystation, profiles showing general down-regulation over time were significantly enriched for proteins associated with translation and ribosome assembly Gene Ontology (GO) terms, while profiles showing up-regulation were significantly enriched for nuclear proteins associated with nucleosome assembly (Table 2). In general, the reverse trend was seen during excystation (Table 3). The results indicate a broad shift from active vegetative growth and protein production to a quiescent form with 'packaged' DNA in cysts. No consistent enrichment for GO terms was seen for encystation profiles peaking at $8 \mathrm{~h}$ or $24 \mathrm{~h}$.

In addition to the temporal expression profiles, significantly differentially expressed genes (false discovery rate $($ FDR $)<0.01$ ) were identified from each pairwise comparison, using Cuffdiff [51] (all FPKM values and significantly differentially expressed genes are shown in Additional file 9). Strikingly, the numbers of genes upand down-regulated at different time points varied greatly (Figure $5 \mathrm{a}$ ). In early encystation ( 8 to $24 \mathrm{~h}$ ) many genes were up-regulated when compared to trophozoites (472 and 900 genes, respectively), but fewer genes were down-regulated (190 and 238 genes, respectively). Later in encystation, this pattern reversed, with more genes down-regulated in 48 and $72 \mathrm{~h}$ cysts (959 and 1,001 genes, respectively) than up-regulated (446 and 578 genes, respectively), relative to trophozoites. During excystation, transcription of many genes is reactivated, with 1,025 genes being up-regulated at $2 \mathrm{~h}$ and 1,032 genes up-regulated at $8 \mathrm{~h}$ (compared to $72 \mathrm{~h}$ cysts) and comparatively fewer genes down-regulated (325 genes and 730 genes, at $2 \mathrm{~h}$ and $8 \mathrm{~h}$, respectively). In general, trends in transcription during encystation are reversed during excystation (Figure 5b). The transcriptional changes during encystation suggest a developmental program activated in early cysts that is later turned off, and down-regulation of genes involved in general metabolic processes as cysts mature; transcription of these genes then resumes during excystation. Overall, approximately 
A

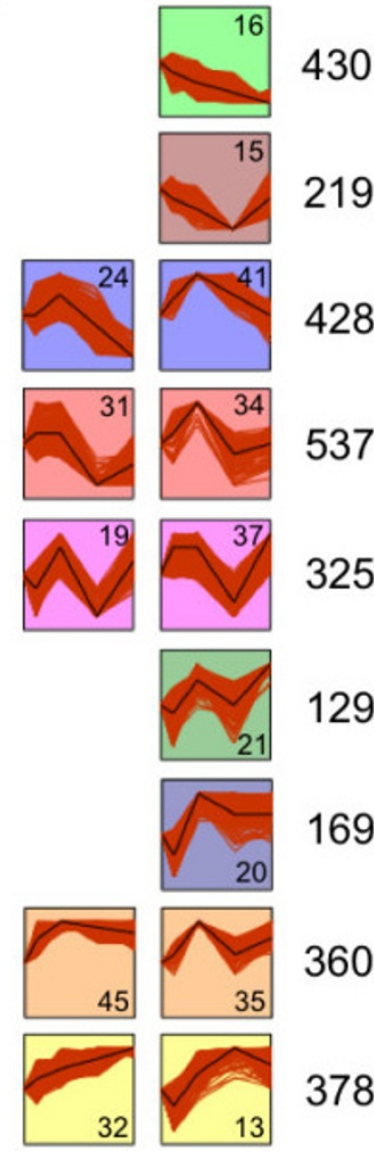

B

45

127
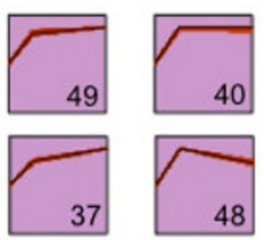

48

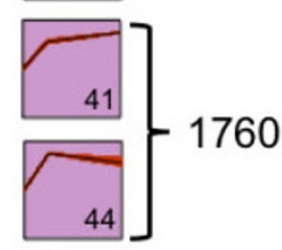

90
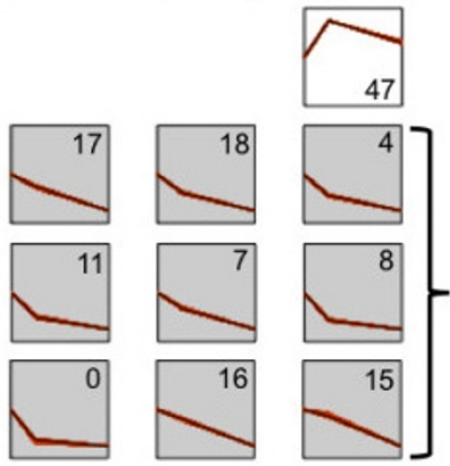

1384
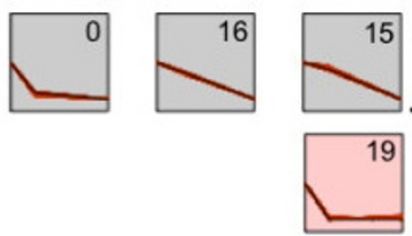

146

Figure 4 Temporal gene expression profiles. Temporal gene expression profiles containing significantly more genes than expected by chance. (a) Expression profiles during encystation. (b) Expression profiles during excystation. Each box shows a representative expression profile (black line) and profiles of genes assigned to the profile (red lines). The profile ID number is shown in each box. Clusters of related profiles have the same color. The numbers of genes assigned to a profile/cluster are shown to the right. All profiles are shown in Additional file 8 and data for all genes are tabulated in Additional file 4.

half of all E. invadens genes (6,168/11,549 total genes) were significantly differentially expressed at at least one time point. This scale of change in the transcriptome has been reported in Plasmodium [19] and Leishmania [52] development, though it sharply contrasts with findings in Giardia lamblia [53], where an extremely limited set of genes showed altered expression during encystation. These differences may indicate variances in the degree to which gene expression at the level of transcription or RNA stability regulates biological processes in these organisms.

RNA-Seq results were confirmed for selected genes by Northern blot analysis of RNA isolated from trophozoites, $24 \mathrm{~h}$ encysting parasites, $72 \mathrm{~h}$ cysts and $8 \mathrm{~h}$ excysting parasites (Figure 6). Two genes with higher expression in trophozoites (EIN_060150, EIN_093390), three genes with higher expression during encystation (EIN_017100, EIN_166570 and EIN_099680), and one gene with increased expression in excystation (EIN_202650) were tested, confirming the patterns of expression identified by RNA-Seq. A gene with stable expression at all time points (EIN_192230) was used as a control. That RNA was derived from different biological samples from those used for RNA-Seq indicates the robustness of the regulation and the reliability of the RNA-Seq results.

\section{Comparison to previous Entamoeba development datasets}

We analyzed the expression of genes previously identified as developmentally regulated in Entamoeba. As expected, genes encoding proteins involved in cyst wall synthesis are highly regulated during development, although interestingly different gene families within this category show distinctive patterns of expression. While the two identified chitin synthase family genes (EIN_040930 and EIN_168780) have increased expression by $8 \mathrm{~h}$ in 
Table 2 Gene Ontology terms associated with temporal gene expression profiles during encystation

\begin{tabular}{|c|c|c|c|}
\hline Profile/cluster $^{a}$ & GO category name & Fold enrichment $^{b}$ & Corrected $P$-value ${ }^{c}$ \\
\hline \multirow[t]{11}{*}{ Profile 16} & Translation & 7.8 & $<0.001$ \\
\hline & Structural constituent of ribosome & 7.9 & $<0.001$ \\
\hline & Ribosome & 8.1 & $<0.001$ \\
\hline & Protein binding & 2.9 & $<0.001$ \\
\hline & Actin binding & 4.9 & $<0.001$ \\
\hline & Glycolysis & 12.2 & $<0.001$ \\
\hline & Intracellular & 1.7 & $<0.001$ \\
\hline & Cytoplasm & 4 & 0.002 \\
\hline & Catalytic activity & 2.3 & 0.002 \\
\hline & Oxidoreductase activity & 3.4 & 0.002 \\
\hline & Oxidation-reduction process & 4 & 0.038 \\
\hline \multirow[t]{10}{*}{ Profile 15} & Translation & 12.1 & $<0.001$ \\
\hline & Structural constituent of ribosome & 11.8 & $<0.001$ \\
\hline & Ribosome & 11 & $<0.001$ \\
\hline & Small ribosomal subunit & 24.3 & $<0.001$ \\
\hline & Intracellular & 2.2 & $<0.001$ \\
\hline & Aminoacyl-tRNA ligase activity & 16.6 & $<0.001$ \\
\hline & tRNA aminoacylation for protein translation & 16.6 & $<0.001$ \\
\hline & Cytoplasm & 6.5 & $<0.001$ \\
\hline & NAD binding & 16.5 & $<0.001$ \\
\hline & Metabolic process & 3 & 0.018 \\
\hline Cluster (profiles 24, 41) & Heat shock protein binding & 6.7 & 0.004 \\
\hline \multirow[t]{3}{*}{ Profile 24} & Heat shock protein binding & 8.5 & 0.006 \\
\hline & Unfolded protein binding & 6.3 & 0.01 \\
\hline & Protein folding & 5.7 & 0.014 \\
\hline \multirow[t]{7}{*}{ Cluster (profiles 31, 34) } & Metabolic process & 3.4 & $<0.001$ \\
\hline & Catalytic activity & 2.5 & $<0.001$ \\
\hline & Binding & 2.3 & $<0.001$ \\
\hline & Phosphatidylcholine-sterol O-acyltransferase activity & 9 & 0.016 \\
\hline & Membrane coat & 5.8 & 0.016 \\
\hline & Structural molecule activity & 6.8 & 0.018 \\
\hline & Vesicle-mediated transport & 3.3 & 0.04 \\
\hline \multirow[t]{8}{*}{ Profile 31} & Metabolic process & 3.5 & $<0.001$ \\
\hline & Catalytic activity & 2.6 & $<0.001$ \\
\hline & Binding & 2.4 & $<0.001$ \\
\hline & Membrane coat & 6.8 & 0.002 \\
\hline & Phosphatidylcholine-sterol O-acyltransferase activity & 10.5 & 0.002 \\
\hline & Structural molecule activity & 7.9 & 0.002 \\
\hline & Vesicle-mediated transport & 3.9 & 0.004 \\
\hline & Lipid metabolic process & 4.9 & 0.034 \\
\hline \multirow[t]{2}{*}{ Profile 19} & Vesicle-mediated transport & 5.1 & 0.062 \\
\hline & Nucleic acid binding & 2.2 & 0.464 \\
\hline \multirow[t]{2}{*}{ Profile 21} & Integral to membrane & 4.7 & 0.014 \\
\hline & Membrane & 4.1 & 0.038 \\
\hline Profile 20 & Hydrolase activity & 4 & 0.014 \\
\hline \multirow[t]{6}{*}{ Cluster (profiles 32 13) } & Methionine adenosyltransferase activity & 30.5 & $<0.001$ \\
\hline & One carbon metabolic process & 30.5 & $<0.001$ \\
\hline & DNA binding & 3.6 & $<0.001$ \\
\hline & Nucleosome & 12.2 & 0.002 \\
\hline & Nucleus & 3 & 0.002 \\
\hline & Nucleosome assembly & 8 & 0.002 \\
\hline
\end{tabular}


Table 2 Gene Ontology terms associated with temporal gene expression profiles during encystation (Continued)

\begin{tabular}{|c|c|c|c|}
\hline & Sequence-specific DNA binding & 6.9 & 0.034 \\
\hline \multirow[t]{4}{*}{ Profile 32} & Methionine adenosyltransferase activity & 48.7 & $<0.001$ \\
\hline & One carbon metabolic process & 48.7 & $<0.001$ \\
\hline & DNA binding & 3.8 & $<0.001$ \\
\hline & Nucleus & 3.3 & 0.01 \\
\hline \multirow[t]{7}{*}{ Profile 13} & Intracellular protein transport & 5.3 & 0.002 \\
\hline & Intracellular & 2.3 & 0.002 \\
\hline & GTP binding & 3.3 & 0.002 \\
\hline & Small GTPase mediated signal transduction & 3.1 & 0.002 \\
\hline & Protein transport & 3.4 & 0.004 \\
\hline & Nucleocytoplasmic transport & 5.6 & 0.016 \\
\hline & GTPase activity & 4.3 & 0.036 \\
\hline
\end{tabular}

${ }^{\mathrm{a}}$ See Figure 4 and Additional file 8 for profiles/clusters. ${ }^{\mathrm{b}}$ Ratio of the observed number of genes with associated GO term to the number expected for a profile of the same size. ${ }^{C} P$-value Bonferroni-corrected for multiple tests.

Table 3 Gene Ontology terms associated with temporal gene expression profiles during excystation

\begin{tabular}{|c|c|c|c|}
\hline Profile/cluster $^{a}$ & GO category name & Fold enrichment $^{b}$ & Corrected $P$-value ${ }^{c}$ \\
\hline \multirow[t]{3}{*}{ Profile 45} & Protein binding & 3.1 & 0.002 \\
\hline & Catalytic activity & 3.4 & 0.002 \\
\hline & Metabolic process & 3.4 & 0.05 \\
\hline \multirow[t]{5}{*}{ Cluster (profiles 49, 40, 41, 37, 48, 44) } & Zinc ion binding & 1.7 & $<0.001$ \\
\hline & Catalytic activity & 1.7 & $<0.001$ \\
\hline & Pyridoxal phosphate binding & 3.7 & 0.024 \\
\hline & Nucleic acid binding & 1.6 & 0.028 \\
\hline & Heat shock protein binding & 3 & 0.032 \\
\hline \multirow[t]{2}{*}{ Profile 49} & Helicase activity & 4.3 & 0.042 \\
\hline & Ubiquitin-dependent protein catabolic process & 4.1 & 0.05 \\
\hline \multirow[t]{2}{*}{ Profile 40} & Binding & 2.1 & 0.01 \\
\hline & Zinc ion binding & 2 & 0.038 \\
\hline Profile 41 & Membrane & 3.7 & 0.006 \\
\hline \multirow[t]{2}{*}{ Profile 37} & Protein binding & 2.4 & 0.022 \\
\hline & Catalytic activity & 2.5 & 0.048 \\
\hline Profile 47 & Oxidoreductase activity & 6.3 & 0.018 \\
\hline \multirow[t]{12}{*}{ Cluster (profiles $0,4,7,8,11,15,16,17,18$ ) } & Ribosome & 3.7 & $<0.001$ \\
\hline & Structural constituent of ribosome & 3.6 & $<0.001$ \\
\hline & Translation & 3.1 & $<0.001$ \\
\hline & Intracellular & 1.5 & $<0.001$ \\
\hline & DNA binding & 2.1 & $<0.001$ \\
\hline & Nucleosome & 5.6 & $<0.001$ \\
\hline & Nucleus & 2.1 & $<0.001$ \\
\hline & Nucleosome assembly & 4 & 0.002 \\
\hline & Signal transduction & 1.6 & 0.024 \\
\hline & Threonine-type endopeptidase activity & 4.2 & 0.044 \\
\hline & Proteasome core complex & 4.2 & 0.044 \\
\hline & Proteolysis involved in cellular protein catabolic process & 4.2 & 0.044 \\
\hline \multirow[t]{4}{*}{ Profile 17} & Ribosome & 7.1 & $<0.001$ \\
\hline & Structural constituent of ribosome & 6.8 & $<0.001$ \\
\hline & Translation & 6.3 & $<0.001$ \\
\hline & Intracellular & 1.9 & 0.002 \\
\hline \multirow[t]{2}{*}{ Profile 18} & Intracellular & 2.1 & 0.006 \\
\hline & Ribosome & 5 & 0.006 \\
\hline
\end{tabular}


Table 3 Gene Ontology terms associated with temporal gene expression profiles during excystation (Continued)

\begin{tabular}{|c|c|c|c|}
\hline & Structural constituent of ribosome & 4.8 & 0.008 \\
\hline & Translation & 4.2 & 0.02 \\
\hline & Signal transduction & 3 & 0.024 \\
\hline \multirow[t]{4}{*}{ Profile 7} & Ribosome & 5.3 & 0.002 \\
\hline & Structural constituent of ribosome & 5.1 & 0.002 \\
\hline & Translation & 4 & 0.012 \\
\hline & DNA binding & 3.1 & 0.04 \\
\hline \multirow[t]{5}{*}{ Profile 8} & Intracellular & 2.3 & 0.01 \\
\hline & Protein transport & 3.6 & 0.012 \\
\hline & GTP binding & 3 & 0.024 \\
\hline & Catalytic activity & 3.2 & 0.024 \\
\hline & Small GTPase mediated signal transduction & 2.9 & 0.032 \\
\hline Profile 16 & DNA binding & 4.4 & $<0.001$ \\
\hline
\end{tabular}

${ }^{a}$ See Figure 4 and Additional file 8 for profiles/clusters. ${ }^{\mathrm{b}}$ Ratio of the observed number of genes with associated GO term to the number expected for a profile of the same size. ${ }^{c} P$-value Bonferroni-corrected for multiple tests.
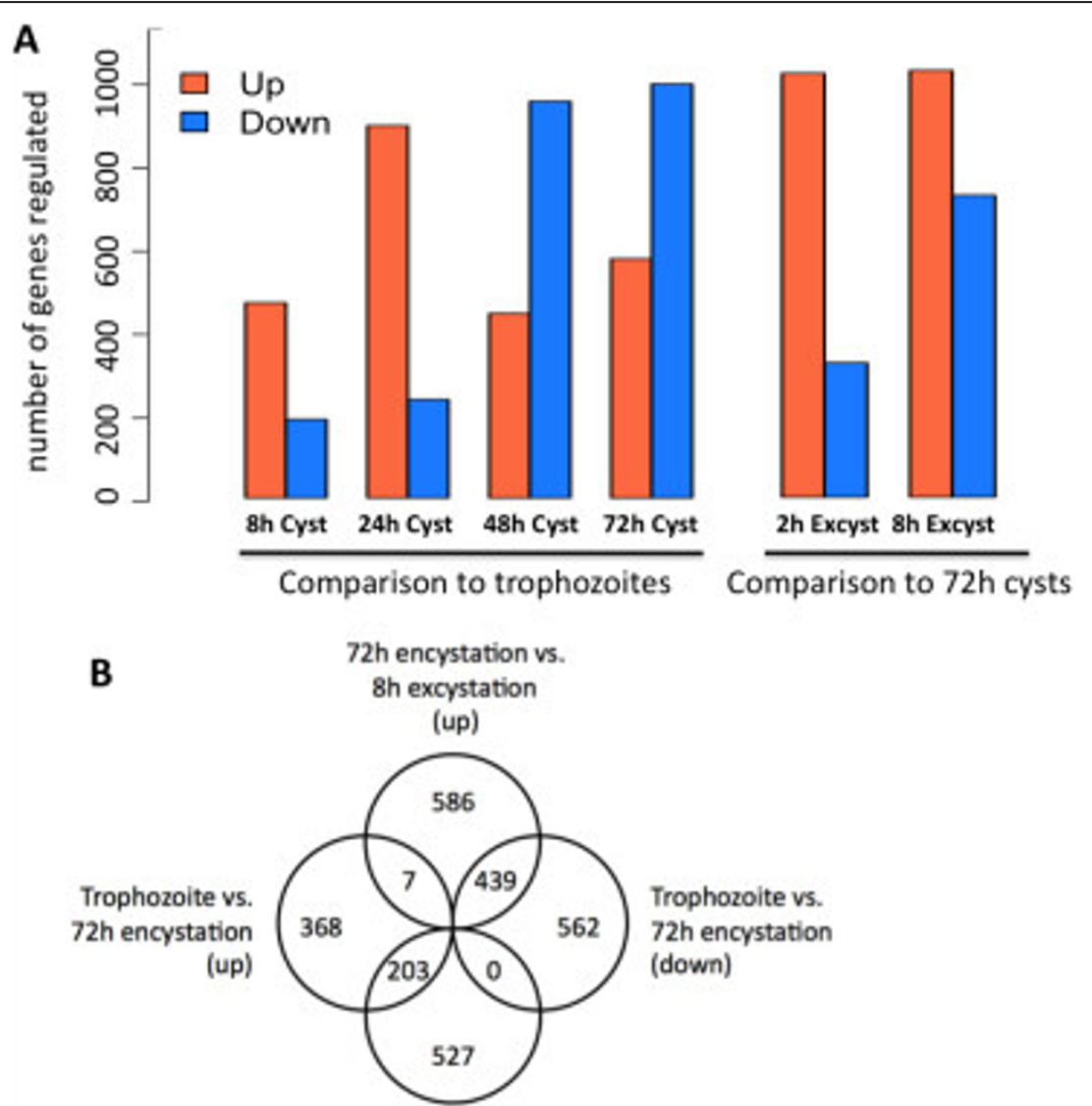

$72 \mathrm{~h}$ encystation vs.
$8 \mathrm{~h}$ excystation
(down)

Figure 5 Genes up-regulated and down-regulated in pairwise comparisons. (a) Total number of genes significantly up- or down-regulated (as determined by Cuffdiff) in $8 \mathrm{~h}, 24 \mathrm{~h}, 48 \mathrm{~h}$ and $72 \mathrm{~h}$ encystation compared to trophozoites, and $2 \mathrm{~h}$ and $8 \mathrm{~h}$ excystation, compared to $72 \mathrm{~h}$ cysts, is shown. (b) Venn diagram showing overlap between the sets of genes up- or down-regulated in $72 \mathrm{~h}$ cysts compared to trophozoites, and genes up- or down-regulated in $8 \mathrm{~h}$ excysting parasites compared to $72 \mathrm{~h}$ cysts. 


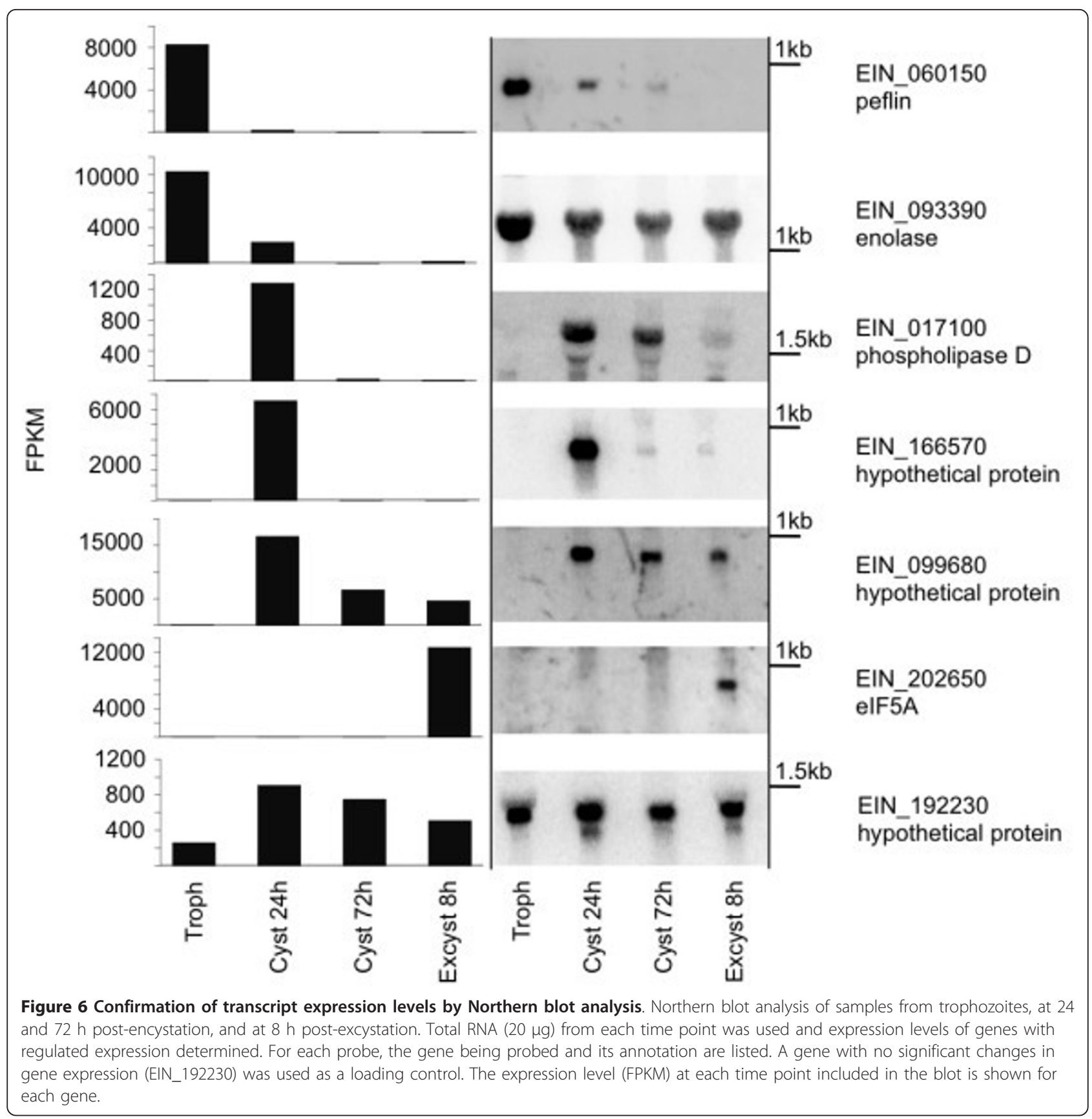

encystation media (Figure 7a), the chitin binding lectins that form the protein component of the cyst wall [54] show varying patterns of expression, with many genes not induced until 24 h (Figure 7b). Interestingly, a chitinase domain containing protein, EIN_084170, was strongly upregulated during excystation, suggesting it could be involved in parasite exit from the cyst (Figure 7c). In addition to these cyst-specific genes, EHI_148790, a member of the gene family of light chain subunits of the amoebic Gal/ GalNac lectin, an important virulence factor in E. histolytica [55], was previously identified as being trophozoite specific in E. histolytica [9]; the putative E. invadens ortholog, EIN_281690 (60\% amino acid identity), was significantly down-regulated in mature (48 to $72 \mathrm{~h}$ ) cysts compared to trophozoites.

Overall, there was significant overlap between genes identified as developmentally regulated in the current RNA-Seq analysis and our previous study of the E. histolytica cyst transcriptome [9]. For the 393 genes up-regulated in E. histolytica cysts that had identifiable $E$. invadens homologs, 90 of the $E$. invadens genes were found to be up-regulated in at least one encystation time point $\left(P \approx 1.4 \times 10^{-7}\right)$. 


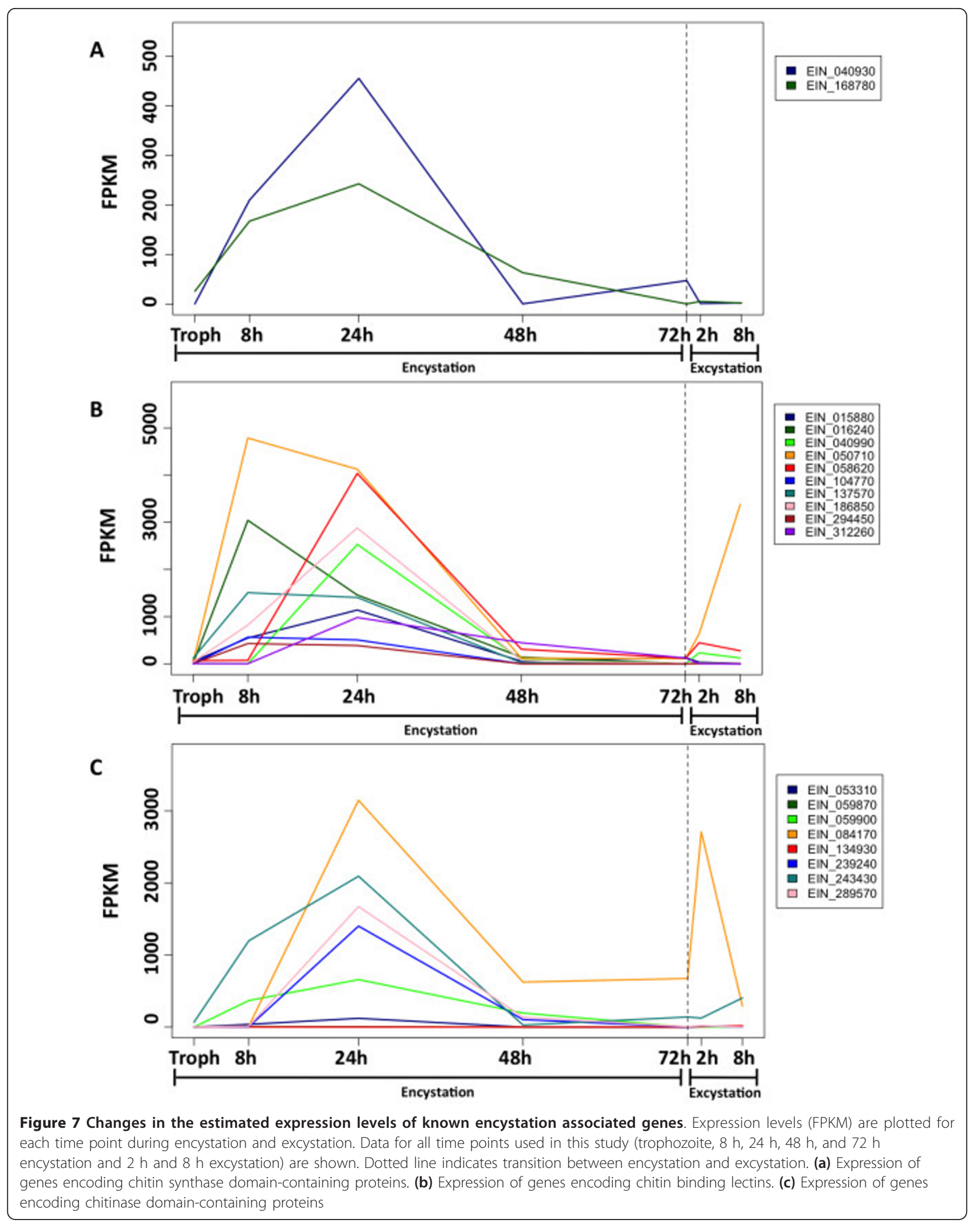


Additionally, 93 genes were up-regulated at 2 or 8 h postexcystation $\left(P \approx 2.5 \times 10^{-10}\right)$, likely due to the fact that the $E$. histolytica cyst transcriptome analysis was performed using an asynchronous population, including both encysting and excysting cells.

Recently, two papers comparing Entamoeba cysts and trophozoites have been published: a proteome of E. histolytica cysts isolated from patient samples [3] and a metabolomic study of encysting E. invadens [56], which reported expression data for a limited number of genes involved in metabolism. Although both studies were limited in scope (417 cyst proteins identified in E. histolytica, and 127 metabolism-related genes analyzed in E. invadens), comparison to our data will still be instructive, as genes or pathways identified as being differentially expressed by two different methods are highly likely to be truly developmentally regulated. However, due to the small number of observations in these studies, many regulated genes were likely missed. Comparison of our results to the cyst proteome showed no significant overlap; of the 195 proteins identified as cystspecific, 74 had identifiable E. invadens orthologs, and only 14 of these were up-regulated in at least one encystation time point. Genes in this category included those involved in cyst wall synthesis, such as the chitin binding protein EIN_040990, alpha-amylase (EIN_052160) and a putative MADS-box transcription factor (EIN_161180). Whether this poor overlap was due to differences in cyst biology between the two species, misidentification of E. invadens orthologs, or reflects a difference between gene expression and protein levels is unclear. However, when our data were compared to the E. invadens microarray data [56], more similarities were identified, with 37 of the 89 genes down-regulated during encystation in the microarray experiment also significantly down-regulated by RNA-Seq $\left(P \approx 9.7 \times 10^{-7}\right)$. Overlap between the upregulated genes was not significant (14 out of the 51 total up-regulated genes), likely because the genes observed by Jeelani et al. [56] were limited to basic metabolic processes, a sample which our data shows was heavily downregulated during encystation. Differences between these two datasets may also reflect differing basal expressions of genes in the trophozoite stage. Genes down-regulated in Jeelani et al. but not in our study generally had low basal expression levels based on the RNA-Seq data; hence, it was not surprising that these genes were not further down-regulated during encystation. The reverse pattern was seen in the up-regulated genes that did not overlap - relatively high basal expression levels - indicating that these genes were already expressed at sufficient levels prior to encystation. These differences in basal expression may be caused by changes to the IP-1 strain during passage in different laboratories or be due to media conditions (LYI-S-2 versus BI-S-33), which could affect expression of metabolic genes. Similar variation between laboratories has been noted in microarray studies of E. histolytica gene expression [57].

\section{Functions of developmentally regulated genes}

To better understand the molecular processes underpinning development, we examined functional domains of regulated genes identified in the pairwise comparisons. Protein sequences for all genes up-regulated early in encystation (8 to 24 h encystation compared to trophozoites), genes up-regulated and down-regulated late in encystation (72 h encystation compared to trophozoites), and genes up-regulated during excystation ( $2 \mathrm{~h}$ excystation compared to mature, $72 \mathrm{~h}$ cysts) were chosen as likely to be the most biologically relevant. The majority of $E$. invadens genes encode hypothetical proteins of unknown function; hence, protein sequences for all significantly regulated genes were obtained from AmoebaDB [58] and searched for functional domains using the Pfam database [47]. Significantly enriched domains were identified by comparing to the frequency of each domain in the whole genome. Selected Pfam domains are shown in Table 4, and a complete list with all significant domains can be found in Additional file 10. To further enhance our understanding of the roles developmentally regulated genes may be playing in stage conversion, we also undertook an analysis of GO term [59] enrichment among significantly regulated genes. The top categories at each analyzed time point are listed in Table 5 and the complete results (all categories with enrichment $P$-values $<0.05$ ) are in Additional file 10.

\section{Early encystation}

Numerous gene families involved in signal transduction were significantly up-regulated early in encystation, including signaling molecules such as protein kinases, small GTPase activating proteins, and lipid signaling proteins. Similar results were seen in E. histolytica cysts, where numerous kinases and other potential signaling pathway members were observed to be up-regulated in cysts [9]. These proteins may be involved in transducing and affecting the signals that trigger encystation. Previous studies using small molecule agonists and inhibitors have suggested pathways that may help trigger stage conversion. Catecholamines, which in vertebrate cells stimulate signaling through the $\beta$-adrenergic receptor, were found to stimulate encystation in E. invadens trophozoites [60]. Interestingly, PLD, which has been found to transduce signals from a receptor in rat cortical astrocytes [61], is strongly up-regulated early in encystation, as well as other potential modulators of G-protein coupled receptor signaling, such as small GTPase activating proteins and phosphatidylinositol 3-kinase (EIN_083000). Regulation of gene expression, whether at the transcriptional or post-transcriptional level, is crucial for stage conversion 
Table 4 Pfam domains enriched in up- and down-regulated genes

\begin{tabular}{|c|c|c|c|c|}
\hline Pfam domain ID & Pfam domain description & Domains in genome ${ }^{b}$ & Domains in subset $^{c}$ & $P$-value ${ }^{d}$ \\
\hline \multicolumn{5}{|c|}{ Up-regulated at $8 \mathrm{~h}$ encystation (compared to trophozoite) } \\
\hline PF00962 & Adenosine/AMP deaminase & 10 & 4 & $1.00 \times 10^{-4}$ \\
\hline PF01370 & NAD dependent epimerase/dehydratase family & 7 & 3 & $6.45 \times 10^{-4}$ \\
\hline PF01380 & Sugar isomerase domain & 3 & 2 & $2.20 \times 10^{-3}$ \\
\hline PF01416 & tRNA pseudouridine synthase & 5 & 2 & $6.92 \times 10^{-3}$ \\
\hline PF06978 & Ribonucleases P/MRP protein subunit POP1 & 2 & 2 & $7.52 \times 10^{-4}$ \\
\hline PF02463 & Structural maintenance of chromosomes superfamily & 9 & 3 & $1.46 \times 10^{-3}$ \\
\hline PF08221 & RNA polymerase III subunit RPC82 helix-turn-helix domain & 3 & 2 & $2.20 \times 10^{-3}$ \\
\hline PF00620 & RhoGAP domain & 97 & 10 & $2.61 \times 10^{-4}$ \\
\hline PF00566 & Rab-GTPase-TBC domain & 62 & 6 & $5.48 \times 10^{-3}$ \\
\hline PF08743 & DNA repair & 3 & 2 & $2.20 \times 10^{-3}$ \\
\hline PF03114 & Protein dimerisation domain & 12 & 3 & $3.53 \times 10^{-3}$ \\
\hline PF09777 & Osteopetrosis-associated transmembrane protein 1 precursor & 2 & 2 & $7.52 \times 10^{-4}$ \\
\hline PF00888 & Cullin family ubiquitin ligase scaffold protein & 11 & 3 & $2.72 \times 10^{-3}$ \\
\hline PF10557 & Cullin protein neddylation domain & 12 & 3 & $3.53 \times 10^{-3}$ \\
\hline PF00643 & B-box zinc finger & 15 & 3 & $6.72 \times 10^{-3}$ \\
\hline PF00578 & Alkyl hydroperoxide reductase and thiol specific antioxidant & 17 & 3 & $9.50 \times 10^{-3}$ \\
\hline PF12796 & Ankyrin repeats & 87 & 9 & $5.03 \times 10^{-4}$ \\
\hline PF03197 & Bacteriophage FRD2 protein & 3 & 2 & $2.20 \times 10^{-3}$ \\
\hline PF07534 & unknown function & 210 & 19 & $4.34 \times 10^{-6}$ \\
\hline \multicolumn{5}{|c|}{ Up-regulated at $24 \mathrm{~h}$ encystation (compared to trophozoite) } \\
\hline PF06045 & Rhamnogalacturonate lyase family & 6 & 5 & $2.74 \times 10^{-6}$ \\
\hline PF00704 & Glycosyl hydrolases family 18 & 7 & 5 & $9.07 \times 10^{-6}$ \\
\hline PF07651 & Phosphatidylinositol 4,5-bisphosphate binding & 8 & 4 & $4.96 \times 10^{-4}$ \\
\hline PF07653 & Variant SH3 domain & 21 & 6 & $6.16 \times 10^{-4}$ \\
\hline PF00018 & SH3 domain: protein-protein interaction & 32 & 7 & $1.19 \times 10^{-3}$ \\
\hline PF00614 & Phospholipase D active site motif & 2 & 2 & $2.98 \times 10^{-3}$ \\
\hline PF00069 & Protein kinase domain & 510 & 41 & $3.42 \times 10^{-3}$ \\
\hline PF00806 & Pumilio-family RNA binding repeat & 60 & 12 & $6.48 \times 10^{-5}$ \\
\hline PF06978 & Ribonucleases P/MRP protein subunit POP1 & 2 & 2 & $2.98 \times 10^{-3}$ \\
\hline PF00352 & Transcription factor TFIID (or TATA-binding protein, TBP) & 11 & 4 & $1.98 \times 10^{-3}$ \\
\hline PF00620 & RhoGAP domain & 97 & 18 & $3.50 \times 10^{-6}$ \\
\hline PF00225 & Kinesin motor domain & 6 & 3 & $2.75 \times 10^{-3}$ \\
\hline PF03953 & Tubulin C-terminal domain & 6 & 3 & $2.75 \times 10^{-3}$ \\
\hline PF00443 & Ubiquitin carboxyl-terminal hydrolase & 29 & 6 & $3.45 \times 10^{-3}$ \\
\hline PF13476 & ATPase domain & 10 & 4 & $1.33 \times 10^{-3}$ \\
\hline PF04506 & Integral membrane protein, possible sugar transporter & 2 & 2 & $2.98 \times 10^{-3}$ \\
\hline PF12796 & Ankyrin repeats & 87 & 13 & $6.03 \times 10^{-4}$ \\
\hline PF07534 & Unknown function & 210 & 31 & $3.07 \times 10^{-7}$ \\
\hline \multicolumn{5}{|c|}{ Up-regulated at $72 \mathrm{~h}$ encystation (compared to trophozoite) } \\
\hline PF00128 & Alpha amylase, catalytic domain & 24 & 7 & $5.95 \times 10^{-5}$ \\
\hline PF02784 & Pyridoxal-dependent decarboxylase, pyridoxal binding domain & 5 & 3 & $8.37 \times 10^{-4}$ \\
\hline PF12697 & Alpha/beta hydrolase family & 8 & 3 & $4.08 \times 10^{-3}$ \\
\hline PF00614 & Phospholipase D active site motif & 2 & 2 & $2.04 \times 10^{-3}$ \\
\hline PF00806 & Pumilio-family RNA binding repeat & 60 & 12 & $1.05 \times 10^{-5}$ \\
\hline PF00773 & Catalytic domain of ribonuclease $\|$ & 10 & 4 & $6.58 \times 10^{-4}$ \\
\hline PF01885 & RNA 2'-phosphotransferase, Tpt1/KptA family & 3 & 2 & $5.83 \times 10^{-3}$ \\
\hline PF06978 & Ribonucleases P/MRP protein subunit POP1 & 2 & 2 & $2.04 \times 10^{-3}$ \\
\hline PF04054 & CCR4-Not complex component - global regulator of transcription & 5 & 3 & $8.37 \times 10^{-4}$ \\
\hline PF00145 & C-5 cytosine-specific DNA methylase & 2 & 2 & $2.04 \times 10^{-3}$ \\
\hline PF08221 & RNA polymerase III subunit RPC82 helix-turn-helix domain & 3 & 2 & $5.83 \times 10^{-3}$ \\
\hline
\end{tabular}


Table 4 Pfam domains enriched in up- and down-regulated genes (Continued)

\begin{tabular}{|c|c|c|c|c|}
\hline \multirow{2}{*}{\multicolumn{5}{|c|}{$5.83 \times 10^{-3}$}} \\
\hline & DNA repair & 3 & 2 & $5.83 \times 10^{-3}$ \\
\hline PF02144 & Repair protein $\operatorname{Rad} 1 / \operatorname{Rec} 1 / \operatorname{Rad} 17$ & 3 & 2 & $5.83 \times 10^{-3}$ \\
\hline PF02145 & Rap/ran-GAP & 33 & 6 & $2.67 \times 10^{-3}$ \\
\hline PF00620 & RhoGAP domain & 97 & 11 & $2.92 \times 10^{-3}$ \\
\hline PF04506 & Integral membrane protein, possible sugar transporter & 2 & 2 & $2.04 \times 10^{-3}$ \\
\hline PF01436 & $\mathrm{NHL}$ repeat & 8 & 3 & $4.08 \times 10^{-3}$ \\
\hline PF05237 & MoeZ/MoeB domain: unknown function & 3 & 2 & $5.83 \times 10^{-3}$ \\
\hline PF07534 & Unknown function & 210 & 20 & $8.17 \times 10^{-4}$ \\
\hline \multicolumn{5}{|c|}{ Up-regulated at $2 \mathrm{~h}$ excystation (compared to $72 \mathrm{~h}$ cyst) } \\
\hline PF00723 & Glycosyl hydrolases family 15 & 6 & 4 & $4.71 \times 10^{-4}$ \\
\hline PF00534 & Glycosyl transferases group 1 & 4 & 3 & $1.75 \times 10^{-3}$ \\
\hline PF01592 & Iron-sulfur cluster assembly & 148 & 24 & $2.86 \times 10^{-4}$ \\
\hline PF00076 & RNA recognition motif (aka RRM, RBD, or RNP domain) & 36 & 9 & $1.11 \times 10^{-3}$ \\
\hline PF00270 & DEAD/DEAH box helicase & 12 & 5 & $1.29 \times 10^{-3}$ \\
\hline PF00565 & Staphylococcal nuclease homolog & 5 & 3 & $4.03 \times 10^{-3}$ \\
\hline PF01416 & Pseudouridine synthesis & 4 & 3 & $1.75 \times 10^{-3}$ \\
\hline PF04719 & hTAFII28-like protein conserved region & 9 & 4 & $3.10 \times 10^{-3}$ \\
\hline PF01926 & 50 S ribosome-binding GTPase & 2 & 2 & $6.08 \times 10^{-3}$ \\
\hline PF02270 & Transcription initiation factor IIF (TFIIF) & 22 & 7 & $8.81 \times 10^{-4}$ \\
\hline PF00226 & DnaJ domain & 4 & 3 & $1.75 \times 10^{-3}$ \\
\hline PF08423 & DNA repair and recombination & 19 & 6 & $2.12 \times 10^{-3}$ \\
\hline PF02450 & Lecithin:cholesterol acyltransferase & 2 & 2 & $6.08 \times 10^{-3}$ \\
\hline PF06728 & GPI transamidase subunit & 2 & 2 & $6.08 \times 10^{-3}$ \\
\hline PF01238 & Phosphomannose isomerase type I & 46 & 10 & $1.81 \times 10^{-3}$ \\
\hline PF00112 & Papain family cysteine protease & 6 & 3 & $7.44 \times 10^{-3}$ \\
\hline PF01067 & Calpain large subunit, domain III (protease) & 28 & 20 & $1.03 \times 10^{-16}$ \\
\hline PF00630 & Filamin/ABP280 repeat & 24 & 9 & $4.09 \times 10^{-5}$ \\
\hline PF01602 & Adaptin N-terminal region & 9 & 6 & $1.47 \times 10^{-5}$ \\
\hline PF04324 & BFD-like [2Fe-2S] binding domain & 4 & 3 & $1.75 \times 10^{-3}$ \\
\hline PF02777 & Iron/manganese superoxide dismutases, C-terminal domain & 8 & 4 & $1.87 \times 10^{-3}$ \\
\hline PF00400 & WD domain, G-beta repeat & 263 & 51 & $7.47 \times 10^{-10}$ \\
\hline PF13115 & YtkA-like: unknown function & 12 & 7 & $9.20 \times 10^{-6}$ \\
\hline PF06229 & FRG1-like family: unknown function & 4 & 3 & $1.75 \times 10^{-3}$ \\
\hline PF08238 & Sel1 repeat & 21 & 6 & $3.60 \times 10^{-3}$ \\
\hline \multicolumn{5}{|c|}{ Down-regulated at $72 \mathrm{~h}$ encystation (compared to trophozoite) } \\
\hline PF00723 & Glycosyl hydrolases family 15 & 6 & 4 & $5.42 \times 10^{-4}$ \\
\hline PF00106 & Short chain dehydrogenase & 12 & 6 & $1.55 \times 10^{-4}$ \\
\hline PF01663 & Type I phosphodiesterase/nucleotide pyrophosphatase & 19 & 7 & $4.13 \times 10^{-4}$ \\
\hline PF02878 & Phosphoglucomutase/phosphomannomutase domain I & 3 & 3 & $5.29 \times 10^{-4}$ \\
\hline PF02880 & Phosphoglucomutase/phosphomannomutase domain III & 3 & 3 & $5.29 \times 10^{-4}$ \\
\hline PF00408 & Phosphoglucomutase/phosphomannomutase, C-terminal domain & 3 & 3 & $5.29 \times 10^{-4}$ \\
\hline PF00349 & Phosphorylates hexoses & 2 & 2 & $6.54 \times 10^{-3}$ \\
\hline PF01467 & Cytidylyltransferase & 9 & 6 & $1.82 \times 10^{-5}$ \\
\hline PF09334 & tRNA synthetases class I (M) & 3 & 3 & $5.29 \times 10^{-4}$ \\
\hline PF00432 & Prenyltransferase and squalene oxidase repeat & 4 & 4 & $4.27 \times 10^{-5}$ \\
\hline PF00630 & Filamin/ABP280 repeat & 28 & 25 & $1.10 \times 10^{-24}$ \\
\hline PF00307 & Calponin homology $(\mathrm{CH})$ domain & 50 & 13 & $9.75 \times 10^{-5}$ \\
\hline PF06268 & Actin cross-linking & 6 & 5 & $1.90 \times 10^{-5}$ \\
\hline PF01602 & Adaptin N-terminal region & 24 & 9 & $5.41 \times 10^{-5}$ \\
\hline PF04324 & BFD-like $[2 \mathrm{Fe}-2 \mathrm{~S}]$ binding domain & 9 & 6 & $1.82 \times 10^{-5}$ \\
\hline PF00248 & Aldo/keto reductase family & 4 & 4 & $4.27 \times 10^{-5}$ \\
\hline PF02777 & Iron/manganese superoxide dismutases, C-terminal domain & 4 & 4 & $4.27 \times 10^{-5}$ \\
\hline
\end{tabular}


Table 4 Pfam domains enriched in up- and down-regulated genes (Continued)

\begin{tabular}{|c|c|c|c|c|}
\hline PF00081 & Iron/manganese superoxide dismutases, alpha-hairpin domain & 5 & 4 & $1.96 \times 10^{-4}$ \\
\hline PF13115 & YtkA-like: unknown function & 12 & 8 & $6.40 \times 10^{-7}$ \\
\hline PF00501 & AMP-binding enzyme & 26 & 11 & $2.08 \times 10^{-6}$ \\
\hline PF12796 & Ankyrin repeats & 87 & 20 & $1.15 \times 10^{-5}$ \\
\hline
\end{tabular}

${ }^{a}$ Selected Pfam domains that were significantly enriched $(P<0.05)$ in genes up- or down-regulated at $8 \mathrm{~h}, 24 \mathrm{~h}$ and $72 \mathrm{~h}$ post-encystation, and at $2 \mathrm{~h}$ postexcystation. ${ }^{\mathrm{b}}$ Number of a Pfam domain in the whole $E$. invadens genome. ${ }^{c}$ Number of a Pfam domain among the subset of regulated genes. ${ }^{\mathrm{d}} P$-value for Pfam domain enrichment.

Table 5 Gene Ontology terms enriched in up- and down-regulated genes

\begin{tabular}{|c|c|c|c|c|}
\hline GO ID & GO category name & Genes in genome ${ }^{\mathrm{b}}$ & Genes in subset $^{c}$ & $P$-value ${ }^{\mathrm{d}}$ \\
\hline \multicolumn{5}{|c|}{ Up-regulated at $8 \mathrm{~h}$ encystation (compared to trophozoite) } \\
\hline GO:0006030 & Chitin metabolism & 5 & 5 & $1.21 \times 10^{-7}$ \\
\hline GO:0006041 & Glucosamine metabolism & 5 & 5 & $1.21 \times 10^{-7}$ \\
\hline GO:0006807 & Nitrogen compound metabolism & 33 & 7 & $3.33 \times 10^{-4}$ \\
\hline GO:0009308 & Amine metabolism & 27 & 6 & $6.94 \times 10^{-4}$ \\
\hline GO:0005975 & Carbohydrate metabolism & 115 & 11 & $7.92 \times 10^{-3}$ \\
\hline GO:0001522 & Pseudouridine synthesis & 7 & 3 & $2.23 \times 10^{-3}$ \\
\hline GO:0007017 & Microtubule-based process & 13 & 4 & $1.57 \times 10^{-3}$ \\
\hline \multicolumn{5}{|c|}{ Up-regulated at $24 \mathrm{~h}$ encystation (compared to trophozoite) } \\
\hline GO:0006030 & Chitin metabolism & 5 & 3 & $4.10 \times 10^{-3}$ \\
\hline GO:0006807 & Nitrogen compound metabolism & 33 & 7 & $1.15 \times 10^{-2}$ \\
\hline GO:0009308 & Amine metabolism & 27 & 6 & $1.52 \times 10^{-2}$ \\
\hline GO:0016311 & Dephosphorylation & 54 & 9 & $2.13 \times 10^{-2}$ \\
\hline GO:0006351 & Transcription, DNA-dependent & 35 & 6 & $4.96 \times 10^{-2}$ \\
\hline GO:0006367 & Transcription initiation from RNA polymerase II promoter & 11 & 3 & $4.78 \times 10^{-2}$ \\
\hline GO:0007017 & Microtubule-based process & 13 & 6 & $2.22 \times 10^{-4}$ \\
\hline GO:0007018 & Microtubule-based movement & 6 & 3 & $7.74 \times 10^{-3}$ \\
\hline \multicolumn{5}{|c|}{ Up-regulated at $72 \mathrm{~h}$ encystation (compared to trophozoite) } \\
\hline GO:0009966 & Regulation of signal transduction & 120 & 13 & $7.62 \times 10^{-3}$ \\
\hline GO:0007275 & Development & 10 & 3 & $1.22 \times 10^{-2}$ \\
\hline GO:0040029 & Regulation of gene expression, epigenetic & 8 & 3 & $6.14 \times 10^{-3}$ \\
\hline GO:0006139 & Nucleobase, nucleoside, nucleotide and nucleic acid metabolism & 328 & 24 & $4.39 \times 10^{-2}$ \\
\hline GO:0051056 & $\begin{array}{l}\text { Regulation of small GTPase mediated } \\
\text { signal transduction }\end{array}$ & 120 & 13 & $7.62 \times 10^{-3}$ \\
\hline GO:0007017 & Microtubule-based process & 13 & 3 & $2.59 \times 10^{-2}$ \\
\hline \multicolumn{5}{|c|}{ Up-regulated at $2 \mathrm{~h}$ excystation (compared to $72 \mathrm{~h}$ cyst) } \\
\hline GO:0019318 & Hexose metabolism & 21 & 8 & $9.38 \times 10^{-4}$ \\
\hline GO:0005975 & Carbohydrate metabolism & 115 & 23 & $2.00 \times 10^{-3}$ \\
\hline GO:0044262 & Cellular carbohydrate metabolism & 35 & 10 & $2.79 \times 10^{-3}$ \\
\hline GO:0006096 & Glycolysis & 7 & 4 & $3.51 \times 10^{-3}$ \\
\hline GO:0006007 & Glucose catabolism & 8 & 4 & $6.42 \times 10^{-3}$ \\
\hline GO:0006006 & Glucose metabolism & 17 & 6 & $6.47 \times 10^{-3}$ \\
\hline GO:0006066 & Alcohol metabolism & 28 & 8 & $7.31 \times 10^{-3}$ \\
\hline GO:0051186 & Cofactor metabolism & 54 & 12 & $1.02 \times 10^{-2}$ \\
\hline GO:0016052 & Carbohydrate catabolism & 10 & 4 & $1.62 \times 10^{-2}$ \\
\hline GO:0016226 & Iron-sulfur cluster assembly & 7 & 4 & $3.51 \times 10^{-2}$ \\
\hline GO:0042254 & Ribosome biogenesis and assembly & 18 & 5 & $3.65 \times 10^{-2}$ \\
\hline GO:0008654 & Phospholipid biosynthesis & 14 & 5 & $1.22 \times 10^{-2}$ \\
\hline GO:0046467 & Membrane lipid biosynthesis & 14 & 5 & $1.22 \times 10^{-2}$ \\
\hline GO:0006644 & Phospholipid metabolism & 25 & 7 & $1.34 \times 10^{-2}$ \\
\hline GO:0006497 & Protein lipidation & 10 & 4 & $1.62 \times 10^{-2}$ \\
\hline GO:0006508 & Proteolysis & 138 & 25 & $5.27 \times 10^{-3}$ \\
\hline
\end{tabular}


Table 5 Gene Ontology terms enriched in up- and down-regulated genes (Continued)

\begin{tabular}{|c|c|c|c|c|}
\hline GO:0006996 & Organelle organization and biogenesis & 112 & 21 & $6.85 \times 10^{-3}$ \\
\hline GO:0006800 & Oxygen and reactive oxygen species metabolism & 5 & 3 & $1.04 \times 10^{-2}$ \\
\hline \multicolumn{5}{|c|}{ Up-regulated at $8 \mathrm{~h}$ excystation (compared to $72 \mathrm{~h}$ cyst) } \\
\hline GO:0006066 & Alcohol metabolism & 28 & 8 & $1.26 \times 10^{-2}$ \\
\hline GO:0005975 & Carbohydrate metabolism & 115 & 22 & $1.30 \times 10^{-2}$ \\
\hline GO:0019752 & Carboxylic acid metabolism & 26 & 8 & $7.82 \times 10^{-3}$ \\
\hline GO:0009059 & Macromolecule biosynthesis & 202 & 34 & $1.72 \times 10^{-2}$ \\
\hline GO:0006260 & DNA replication & 56 & 12 & $2.65 \times 10^{-2}$ \\
\hline GO:0006139 & Nucleobase, nucleoside, nucleotide and nucleic acid metabolism & 328 & 50 & $2.69 \times 10^{-2}$ \\
\hline GO:0006259 & DNA metabolism & 144 & 25 & $2.71 \times 10^{-2}$ \\
\hline GO:0016568 & Chromatin modification & 11 & 4 & $3.17 \times 10^{-2}$ \\
\hline GO:0006629 & Lipid metabolism & 71 & 19 & $3.61 \times 10^{-4}$ \\
\hline GO:0008610 & Lipid biosynthesis & 21 & 7 & $7.88 \times 10^{-3}$ \\
\hline GO:0044255 & Cellular lipid metabolism & 38 & 10 & $1.02 \times 10^{-2}$ \\
\hline GO:0008654 & Phospholipid biosynthesis & 14 & 5 & $1.78 \times 10^{-2}$ \\
\hline GO:0006644 & Phospholipid metabolism & 25 & 7 & $2.15 \times 10^{-2}$ \\
\hline GO:0006497 & Protein lipidation & 10 & 4 & $2.22 \times 10^{-2}$ \\
\hline GO:0006508 & Proteolysis & 138 & 25 & $1.65 \times 10^{-2}$ \\
\hline GO:0006996 & Organelle organization and biogenesis & 112 & 21 & $1.87 \times 10^{-2}$ \\
\hline \multicolumn{5}{|c|}{ Down-regulated at $8 \mathrm{~h}$ encystation (compared to trophozoite) } \\
\hline GO:0009309 & Amine biosynthesis & 10 & 3 & $1.38 \times 10^{-3}$ \\
\hline GO:0006519 & Amino acid and derivative metabolism & 23 & 4 & $1.86 \times 10^{-3}$ \\
\hline GO:0005975 & Carbohydrate metabolism & 115 & 8 & $5.37 \times 10^{-3}$ \\
\hline GO:0019752 & Carboxylic acid metabolism & 26 & 3 & $2.27 \times 10^{-2}$ \\
\hline GO:0051186 & Cofactor metabolism & 54 & 4 & $3.81 \times 10^{-2}$ \\
\hline GO:0016226 & Iron-sulfur cluster assembly & 7 & 4 & $9.80 \times 10^{-6}$ \\
\hline GO:0050896 & Response to stimulus & 46 & 4 & $3.14 \times 10^{-2}$ \\
\hline GO:0006323 & DNA packaging & 39 & 4 & $1.81 \times 10^{-2}$ \\
\hline GO:0051276 & Chromosome organization and biogenesis & 43 & 4 & $2.52 \times 10^{-2}$ \\
\hline GO:0006259 & DNA metabolism & 144 & 8 & $3.36 \times 10^{-2}$ \\
\hline GO:0046467 & Membrane lipid biosynthesis & 14 & 3 & $3.90 \times 10^{-3}$ \\
\hline GO:0006644 & Phospholipid metabolism & 25 & 3 & $2.04 \times 10^{-2}$ \\
\hline GO:0006497 & Protein lipidation & 10 & 3 & $1.38 \times 10^{-3}$ \\
\hline \multicolumn{5}{|c|}{ Down-regulated at $24 \mathrm{~h}$ encystation (compared to trophozoite) } \\
\hline GO:0005975 & Carbohydrate metabolism & 115 & 7 & $2.99 \times 10^{-2}$ \\
\hline GO:0050896 & Response to stimulus & 46 & 4 & $3.14 \times 10^{-2}$ \\
\hline GO:0006323 & DNA packaging & 39 & 4 & $1.81 \times 10^{-2}$ \\
\hline GO:0051276 & Chromosome organization and biogenesis & 43 & 4 & $2.52 \times 10^{-2}$ \\
\hline GO:0006259 & DNA metabolism & 144 & 8 & $3.36 \times 10^{-2}$ \\
\hline GO:0031497 & Chromatin assembly & 30 & 3 & $4.27 \times 10^{-2}$ \\
\hline GO:0006461 & Protein complex assembly & 31 & 3 & $4.64 \times 10^{-2}$ \\
\hline \multicolumn{5}{|c|}{ Down-regulated at $72 \mathrm{~h}$ encystation (compared to trophozoite) } \\
\hline GO:0006096 & Glycolysis & 7 & 5 & $2.22 \times 10^{-4}$ \\
\hline GO:0019320 & Hexose catabolism & 8 & 5 & $5.42 \times 10^{-4}$ \\
\hline GO:0046365 & Monosaccharide catabolism & 8 & 5 & $5.42 \times 10^{-4}$ \\
\hline GO:0006007 & Glucose catabolism & 8 & 5 & $5.42 \times 10^{-4}$ \\
\hline GO:0005996 & Monosaccharide metabolism & 22 & 8 & $1.19 \times 10^{-3}$ \\
\hline GO:0005975 & Carbohydrate metabolism & 115 & 23 & $1.58 \times 10^{-3}$ \\
\hline GO:0006092 & Main pathways of carbohydrate metabolism & 12 & 5 & $5.35 \times 10^{-3}$ \\
\hline GO:0016052 & Carbohydrate catabolism & 10 & 5 & $2.04 \times 10^{-3}$ \\
\hline GO:0016226 & Iron-sulfur cluster assembly & 7 & 4 & $3.28 \times 10^{-3}$ \\
\hline GO:0031163 & Metallo-sulfur cluster assembly & 7 & 4 & $3.28 \times 10^{-3}$ \\
\hline
\end{tabular}


Table 5 Gene Ontology terms enriched in up- and down-regulated genes (Continued)

\begin{tabular}{|c|c|c|c|c|}
\hline GO:0006629 & Lipid metabolism & 71 & 15 & $5.95 \times 10^{-3}$ \\
\hline GO:0051258 & Protein polymerization & 4 & 3 & $4.29 \times 10^{-3}$ \\
\hline GO:0030036 & Actin cytoskeleton organization and biogenesis & 7 & 4 & $3.28 \times 10^{-3}$ \\
\hline GO:0030041 & Actin filament polymerization & 4 & 3 & $4.29 \times 10^{-3}$ \\
\hline GO:0008154 & Actin polymerization and/or depolymerization & 4 & 3 & $4.29 \times 10^{-3}$ \\
\hline GO:0016043 & Cell organization and biogenesis & 306 & 51 & $3.70 \times 10^{-4}$ \\
\hline GO:0006996 & Organelle organization and biogenesis & 112 & 21 & $5.58 \times 10^{-3}$ \\
\hline GO:0006800 & Oxygen and reactive oxygen species metabolism & 5 & 4 & $5.58 \times 10^{-4}$ \\
\hline GO:0006801 & Superoxide metabolism & 5 & 4 & $5.58 \times 10^{-4}$ \\
\hline \multicolumn{5}{|c|}{ Down-regulated at $2 \mathrm{~h}$ excystation (compared to $72 \mathrm{~h}$ cyst) } \\
\hline GO:0007154 & Cell communication & 566 & 23 & $3.73 \times 10^{-2}$ \\
\hline GO:0016043 & Cell organization and biogenesis & 306 & 14 & $4.47 \times 10^{-2}$ \\
\hline \multicolumn{5}{|c|}{ Down-regulated at $8 \mathrm{~h}$ excystation (compared to $72 \mathrm{~h}$ cyst) } \\
\hline GO:0008643 & Carbohydrate transport & 5 & 3 & $3.56 \times 10^{-3}$ \\
\hline GO:0044249 & Cellular biosynthesis & 276 & 51 & $1.18 \times 10^{-10}$ \\
\hline GO:0006412 & Protein biosynthesis & 194 & 44 & $2.14 \times 10^{-12}$ \\
\hline GO:0006414 & Translational elongation & 11 & 3 & $4.21 \times 10^{-2}$ \\
\hline GO:0051276 & Chromosome organization and biogenesis & 43 & 9 & $3.42 \times 10^{-3}$ \\
\hline GO:0006323 & DNA packaging & 39 & 8 & $6.49 \times 10^{-3}$ \\
\hline GO:0031497 & Chromatin assembly & 30 & 6 & $2.01 \times 10^{-2}$ \\
\hline GO:0006334 & Nucleosome assembly & 23 & 6 & $5.27 \times 10^{-3}$ \\
\hline GO:0006461 & Protein complex assembly & 31 & 7 & $6.20 \times 10^{-3}$ \\
\hline GO:0016043 & Cell organization and biogenesis & 306 & 32 & $2.40 \times 10^{-2}$ \\
\hline GO:0006996 & Organelle organization and biogenesis & 112 & 14 & $3.41 \times 10^{-2}$ \\
\hline
\end{tabular}

${ }^{\mathrm{a}}$ Selected GO terms that were significantly enriched $(P<0.05)$ in genes up- or down-regulated at $8 \mathrm{~h}, 24 \mathrm{~h}$ and $72 \mathrm{~h}$ post-encystation, and at $2 \mathrm{~h}$ post-

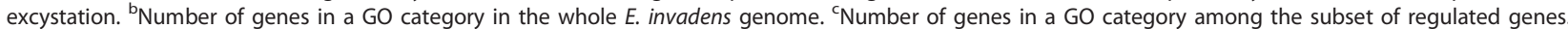

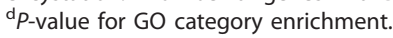

in many parasite species [62-64]. We found that Pfam domains associated with transcriptional regulation, such as helix-turn-helix motif DNA binding proteins and basal transcription factors such as the TATA binding protein, were highly enriched in genes up-regulated in early encystation. Multiple Myb family domain protein genes are regulated during development, including one (EIN_241120) that is highly homologous to the SHAQKY domain protein identified in E. histolytica (originally identified in [29] as EIN_052670). These transcription factors may drive cell fate decisions during encystation by promoting expression of cyst-specific genes.

Interestingly, RNA metabolism was also regulated during encystation, with RNA binding proteins, RNAseP domain proteins, and the RNA-editing protein pseudouridine synthase (EIN_156980) up-regulated in early cysts. This last gene is particularly interesting, as in the apicomplexan parasite Toxoplasma gondii mutations in PUS1, an RNA pseudouridine synthase, were found to sharply decrease rates of differentiation from the tachyzoite to bradyzoite forms [65]; it is possible that a similar dependence on RNA editing is found in Entamoeba development. In observing the enriched GO terms, we found, as expected, that genes involved in glucosamine metabolism (GO:0006041), important for cyst wall synthesis, are up-regulated early in encystation. Additional GO terms enriched among early up-regulated genes include microtubule based processes (GO:0007017) and DNA dependent transcription (GO:0006351).

\section{Late encystation}

Many down-regulated genes in mature cysts encode proteins involved in basic metabolic processes, such as phosphoglucomutase (EIN_242460), hexokinases (EIN_040150, EIN_015200) and short-chain dehydrogenases (EIN_315930, EIN_147830, EIN_239670, EIN_222000, EIN_039970, EIN_243560). This finding is consistent with recent work [56] in which the metabolome of encysting $E$. invadens was determined. In this study it was observed that during encystation and in mature cysts ( $48 \mathrm{~h}$ and $120 \mathrm{~h}$ post-encystation), basic metabolic processes such as glycolysis were drastically decreased, and glucose metabolism redirected to cyst wall synthesis. Similar to the findings in E. histolytica [9], numerous virulence factors were also downregulated in mature cysts, which may be expected as this stage does not cause disease symptoms in the host. In addition to constituents of the Gal/GalNac lectin complex previously mentioned, genes of the serine, 
threonine, isoleucine rich proteins (STIRP) (EIN_110790), rhomboid protease (EIN_219350, EIN_255710) and peroxiredoxin (EIN_174460, EIN_130760, EIN_004350 and EIN_076200) families, which have demonstrated virulence activities in E. histolytica [66-68], have decreased expression in mature cysts compared to trophozoites.

RNA metabolism continues to be regulated in mature cysts, with multiple Pumilio homology domain proteins (EIN_033210, EIN_156840) and the ribonucleoprotein EIN_004530 being up-regulated. These proteins may be involved in formation of the chromatoid bodies, RNP structures that are found in Entamoeba cysts [69]. In addition, DNA repair pathway genes such as the Rad1 homolog EIN_013450 and the Rad52 homolog EIN_094590 have increased expression and may facilitate nuclear division, which occurs late in encystation [70]. Interestingly, DNA repair genes were previously observed to be a significantly enriched group among genes up-regulated in E. histolytica cysts [9], indicating that they may be involved in a process common to encystation in all Entamoeba species. Consistent with recent findings that levels of most amino acids decrease in encystation [56], genes involved in amino acid metabolism (GO:0006519) are down-regulated. Later in encystation, chromatin assembly (GO:0006333) and DNA metabolism (GO:0006139) genes are up-regulated. As with the DNA repair-related genes noted earlier, genes in these groups may be important for nuclear division. Consistent with our Pfam family analysis, carbohydrate metabolism (GO:0005975) was significantly enriched in genes down-regulated at 48 and $72 \mathrm{~h}$ of encystation. In addition, other metabolic pathways, including lipid metabolism (GO:0006629) and biosynthesis (GO:0009058), are reduced in mature cysts.

\section{Excystation}

The down-regulation of carbohydrate metabolism observed in mature cysts is reversed during excystation, with increased transcript levels of glycoside hydrolases (EIN_135910, EIN_106440) as well as the hexokinases that had been down-regulated during encystation. Other gene families up-regulated during excystation include likely regulators of transcription, such as TFIID (EIN_111320), and protein synthesis, such as tRNA synthetases (EIN_222960, EIN_156340) and a PIG-U that is involved in GPI-anchor synthesis (EIN_019990). Regulation of these genes is consistent with synthesis of proteins required for trophozoite function. Our finding that cysteine proteases are significantly up-regulated during excystation is consistent with data showing that cysteine protease inhibitors inhibit excystation [71], and may indicate a role for these proteases in degrading the cyst wall. GO analysis showed that glycolytic pathways (GO:0006096), lipid biosynthesis (GO:0008610) and ribosome assembly (GO:0042254) genes show increased expression in excysting parasites.
Meiosis-specific genes are upregulated during encystation In common with many protozoa for which no sexually dimorphic forms could be identified (for example, kinetoplastids, Giardia, trichomonads), the Entamoebae were long thought to be asexual. However, many of these protozoa show evidence of sexuality (meiotic cell division and genetic exchange) [72-74]. Comparative analysis of many eukaryotic species has shown that E. histolytica contains most of the machinery required for meiosis [73], and our orthology analysis identified these genes in E. invadens. Additionally, a previous analysis of E. histolytica genomes demonstrated haplotype structures that strongly suggest sexual recombination [75]. However, how and when recombination occurs is not known. Nuclear division occurs during encystation as trophozoites have one nucleus while cysts (of $E$. invadens and E. histolytica, though not all Entamoeba species) have four $[70,76]$. We hypothesize that meiosis occurs during encystation, with the two divisions (meiosis I and meiosis II) resulting in four haploid nuclei.

We analyzed the expression patterns of meiosis-specific genes (those genes that are only involved in meiosis) and all meiosis genes (including genes that are also involved in other nuclear maintenance processes, including mitosis) [73]. Figure 8 shows the median and distribution of expression values of all genes in these groups; Additional file 11 gives the FPKM for each gene. The data demonstrate clear up-regulation of expression in all meiosisassociated and meiosis-specific genes at 24 hours after the induction of encystation. Meiosis-specific MND1 (EIN_051380) and HOP2 (EIN_249340) form a complex to bind to DNA at double strand breaks [77]. They are both very strongly up-regulated in our data with the highest FPKM values of all the meiosis genes at $8 \mathrm{~h}$ and $24 \mathrm{~h}$ of encystation. MND1, which stabilizes the heteroduplex after double strand break formation is upregulated four-fold at $24 \mathrm{~h}$ of encystation. DMC1 (EIN_249340), a meiosis homolog of RAD52 [78], which promotes recombination between homologs, is massively up-regulated at $24 \mathrm{~h}(\mathrm{FPKM}=3.7$ at $0 \mathrm{~h}$ and 263.6 at $24 \mathrm{~h}$ of encystation) before returning to low level expression at $72 \mathrm{~h}(\mathrm{FPKM}=0.8)$. Its mitotic homolog RAD52 (EIN_094590) remains up-regulated after 24 h. MSH4 and MSH5 (EIN_222600, EIN_020760) are meiosisspecific and form a heterodimer involved in Holliday junction resolution [79]; the $\mathrm{MSH} 4$ gene has very low levels of transcription and is detected only at $8 \mathrm{~h}$ during encystation whereas MSH5 shows peak levels at $24 \mathrm{~h}$. Global analysis of the meiosis-associated but non-specific genes also shows a clear pattern of up-regulation at approximately $24 \mathrm{~h}$ during encystation. This is consistent with the data on meiosis-specific genes and supports our hypothesis that meiosis is occurring during cyst formation. 


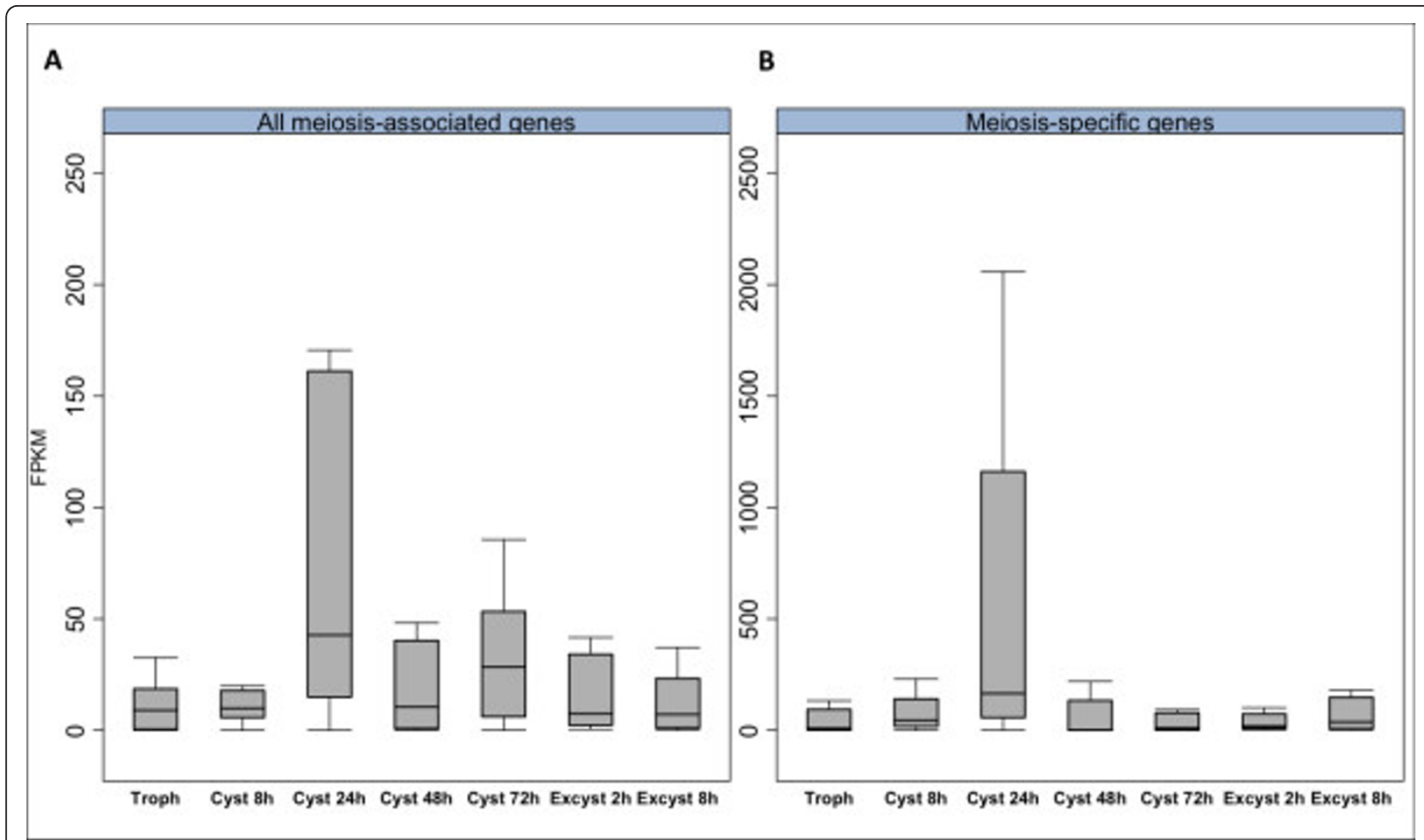

Figure 8 Changes in expression levels of genes involved in meiosis. $(\mathbf{a}, \mathbf{b})$ Boxplots showing the distribution of expression values at each time point during encystation and excystation for meiosis-associated but not meiosis-specific genes (a) and for genes with meiosis-specific roles (b). There is a trend towards increased expression at $24 \mathrm{~h}$ after induction of encystation. This pattern of expression is consistent with a model in which meiotic division gives rise to the four nuclei in the cyst.

Meiosis during encystation is consistent with cysts being a dispersal stage for the parasite. Genetic exchange and expression of meiosis-specific genes has also been described in Giardia cysts, although the process involved may be non-meiotic [74]. During dispersal, it could be advantageous for the parasite to recombine, as this may enable it to infect more diverse hosts. In Entamoeba it is not yet proven that recombination occurs, but if the nuclei in the cysts are haploid, then there must be some form of nuclear fusion during excystation in order to produce diploid trophozoites.

\section{Phospholipase $D$ is required for efficient encystation in E. invadens}

Among the genes with increasing expression during encystation was that encoding PLD, an enzyme involved in lipid second messenger signaling. PLD catalyzes the conversion of phosphatidyl choline to phosphatidic acid and has been linked to many important biological processes, including vesicle transport and transduction of signals required for cell shape changes and proliferation [80,81]. E. invadens has two genes encoding PLDs: EIN_017100 and EIN_196230. Both are highly upregulated during encystation (Figure 9a). PLD was also up-regulated in E. histolytica cysts [9].
To determine if there was a regulatory role for PLD in encystation, we undertook functional studies. First, we examined changes in PLD activity during development. Using the Amplex Red Phospholipase D Assay kit (Molecular Probes), we assayed PLD activity in whole cell lysates at $2 \mathrm{~h}, 5 \mathrm{~h}, 10 \mathrm{~h}, 24 \mathrm{~h}$ and $48 \mathrm{~h}$ after transfer to encystation media (Figure 9b). We found that PLD activity increased during encystation, peaking early $(5 \mathrm{~h})$ and falling back below trophozoite levels later in encystation (24 to $48 \mathrm{~h}$ ). This pattern of activity supports a role for PLD during encystation; however, it does not coincide with peak RNA levels of the PLD genes determined by RNA-Seq, likely indicating that PLD activity is being regulated at the protein level. It should be noted that the activity assay cannot distinguish between the products of the two PLD genes; hence, differing activity levels for the two enzymes could further complicate the relationship between activity and gene expression.

We then tested whether inhibition of PLD activity affected encystation efficiency. PLD inhibition was achieved by addition of $0.6 \%$ n-butanol, which acts as a non-productive substrate for PLD, suppressing formation of phosphatidic acid [82]; the same amount of tertbutanol, which has no effect on PLD activity, was used as a control. N-butanol was added to encystation media 
A

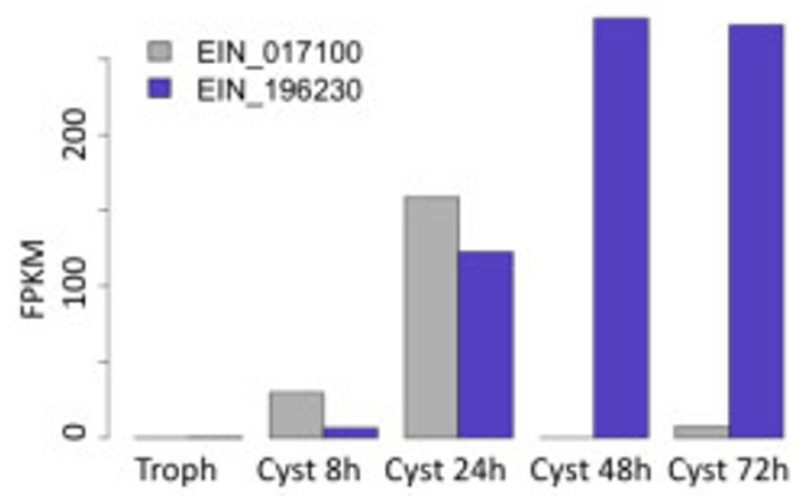

C

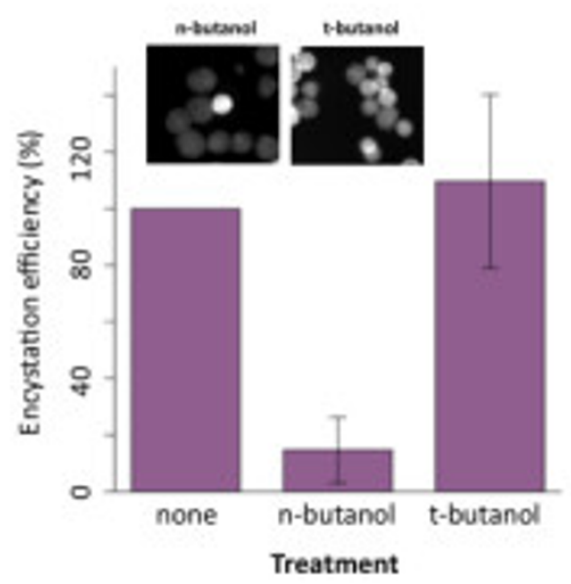

B

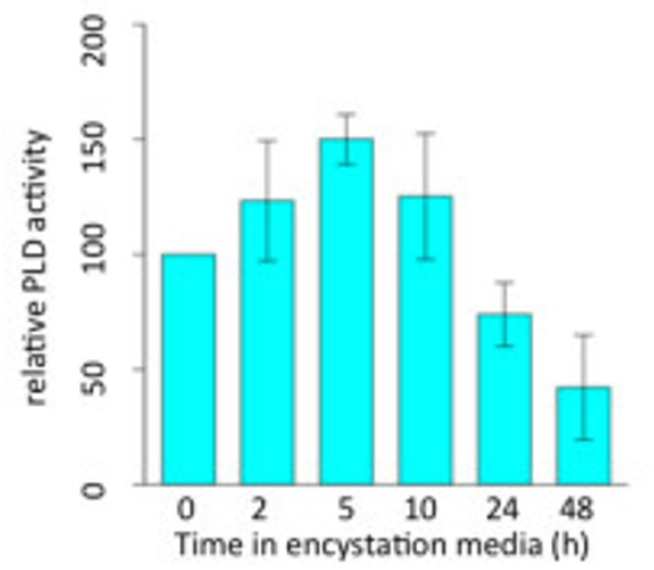

D

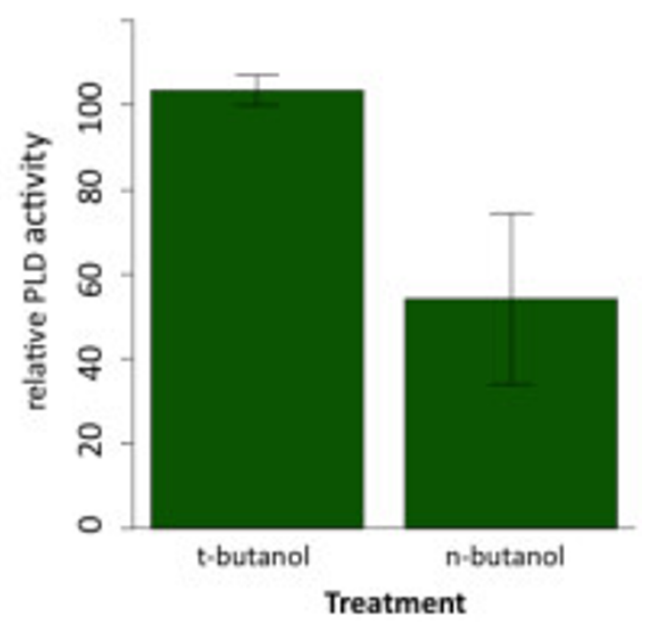

Figure 9 Phospholipase D expression and function during encystation. The potential role of PLD in encystation was examined by observing the changes in expression and enzyme activity, and the effect of inhibition of PLD on encystation efficiency. (a) Expression of two E. invadens PLD genes. FPKM values for EIN_017100 and EIN_196230 at each encystation time point are shown. (b) PLD enzyme activity was measured using the Amplex Red Phospholipase D kit (Molecular Probes). Relative activity (measured as fluorescence at $585 \mathrm{~nm}$ and normalized to trophozoite activity) is shown for each time point. Error bars indicate \pm standard deviation. (c) Inhibition of PLD decreases encystation efficiency. Encysting cultures of $E$. invadens were either untreated, treated with $0.6 \% \mathrm{n}$-butanol (an inhibitor of PLD activity) or with $0.6 \%$ t-butanol (which has no effect on PLD activity). Significant reduction of encystation efficiency $(P<0.01)$ was seen with n-butanol treatment, when compared to untreated parasites, but efficiency did not change with addition of t-butanol. Error bars indicate \pm standard deviation. Insets show representative images of $n$-butanol and t-butanol treated samples, stained with calcofluor, which labels cysts. Note the higher percentage of positively staining cells in the t-butanol treated sample. (d) Inhibition of E. invadens PLD by n-butanol. To confirm that the effect of n-butanol on encystation was due to inhibition of PLD, enzyme activity of trophozoite lysate was measured in the presence of either $\mathrm{n}$ - or $\mathrm{t}$-butanol. Relative activity (measured as fluorescence at $585 \mathrm{~nm}$ and normalized to activity in untreated lysate) is shown for each condition. Error bars indicate \pm standard deviation.

upon introduction of encystation in trophozoites; encystation was allowed to proceed for $48 \mathrm{~h}$, after which encystation efficiency was assayed by treatment with $0.1 \%$ sarkosyl. We found a marked reduction of encystation efficiency (approximately $22 \%$ of untreated levels, $P<0.01$ ) in the $\mathrm{n}$-butanol treated samples (Figure 9c); however, cysts that formed in n-butanol treated cultures were normal in size and gross morphology. Addition of t-butanol had no significant effect on encystation, confirming the specificity of the n-butanol repression of encystation. To ensure that this effect was indeed due to inhibition of PLD by n-butanol, we tested susceptibility of the E. invadens PLD to butanol using the activity assay described above. We found that addition of $0.6 \%$ 
n-butanol to the reaction mixture significantly reduced PLD activity, while no effect was seen with the same amount of t-butanol (Figure 9d). These results indicate that PLD could be an important regulator of encystation in Entamoeba. Whether PLD is required for transduction of the initial signals that trigger encystation, perhaps via a G-protein coupled receptor, or is a downstream effector will require further study.

PLD has been implicated in cell fate regulation and other developmental processes in a wide range of species, including zoospore differentiation in the fungus Phytophthora infestans [83], quorum sensing in Dictyostelium [84] and regulation of proliferation in mammalian systems $[61,80]$, where extensive crosstalk between PLD signaling and other critical pathways such as sphingolipid signaling and protein kinase $\mathrm{C}$ has been documented $[85,86]$. In addition to PLD, other potential regulators of lipid signaling and protein kinase $\mathrm{C}$ activity are up-regulated during encystation, including diacyglycerol kinase (EIN_094160), phosphoinositol 3-kinase (EIN_083000) and a homolog of ceramide synthase (EIN_255100), potentially indicating a role for these pathways in encystation. Further investigation will be required to determine if PLD and protein kinase $C$ pathways interdigitate in Entamoeba as they do in other systems, and to identify how they contribute to the signaling network controlling development. The identification of a regulator of encystation by finding genes with differential expression by RNA-Seq suggests that this data set will be an important source of information about Entamoeba development, and provide many targets for future inquiry, including potential genes to target for inhibition of stage conversion.

\section{Conclusions}

Encystation and excystation are vital for dispersal and pathogenicity in some of the most important intestinal pathogens affecting humans, including Giardia, Cryptosporidium and Entamoeba, and their potential as targets for therapeutic intervention has recently been highlighted [87]. However, encysting organisms can be very distantly related and it is unlikely that they have conserved many of the mechanistic features of the process over these long evolutionary periods; rather, these similarities may represent convergent adaptation to analogous lifestyles and environments. By understanding the similarities between these processes, we can begin to understand common selective forces acting on these parasites and potentially common therapeutic targets. The genomic and transcriptomic data described in this paper will lay the foundation for functional studies of the developmental cycle in Entamoeba. Our study has shown a number of important similarities between the processes in Giardia and Entamoeba, including down-regulation of basic metabolic processes $[88,89]$, meiotic division, and involvement of Myb domain transcription factors and lipid signaling pathways. We have also described potential signaling mechanisms that could be involved in triggering the encystation process. These genome-wide datasets lay the groundwork for future mechanistic dissection of the developmental cascade and identification of new targets for diagnostic or treatment approaches.

\section{Materials and methods}

\section{E. invadens genome assembly and gene prediction}

The sequenced strain of E. invadens, IP-1, was originally isolated from a natural infection of a painted turtle, C. picta, and was pathogenic in snakes [5]. The genome was sequenced at the J Craig Venter Institute (JCVI) sequencing center. Genomic DNA was sheared by sonication and cloned into pHOS2 plasmid vectors to generate small (1.5 to $2 \mathrm{~kb}$ ) and medium (4 to $5 \mathrm{~kb}$ ) insert libraries, which were sequenced using dye terminator sequencing on ABI 3730 sequencers, generating 294,620 reads. Reads were trimmed with UMD Overlapper [90] to determine a clear range for every read. Those with $>98 \%$ BLASTN identity to the rRNA sequence of $E$. invadens were removed prior to genome assembly, as were tRNA sequences identified by tRNAscan-SE [91]. The remaining reads were assembled with Celera Assembler version 3.10 [23]. The following non-standard assembly options were used: the meryl K-mer frequency limit was set to 1,000 $($ default $=100)$ to allow more repetitive regions to seed overlaps; the assumed error rate for building unitigs was set to $0.5 \%$ (default $=1.5 \%$ ) to separate similar repeats; the genome size (default $=$ none) was set to $10 \mathrm{Mbp}$ to reduce sensitivity to coverage-based repeat detection. The assembly ran on AMD Opteron processors with 64 GB RAM and the Suse 10.1 Linux operating system.

Generation of gene models for E. invadens was performed using a combination of de novo gene finders and homology based methods, utilizing the E. histolytica proteome as a reference. GeneZilla [92], Augustus [93] and Twinscan [94] were trained on a set of 500 manually curated gene models annotated using E. histolytica protein alignments. Protein alignments were performed with the Analysis and Annotation Tool (AAT) [95]. A final gene set was obtained using EVM, a consensus-based evidence modeler developed at JCVI [96].

The final consensus gene set was functionally annotated using the following programs: PRIAM [97] for enzyme commission (EC) number assignment, hidden Markov model (HMM) searches using Pfam [98] and TIGRfam [99] to discover conserved protein domains, BLASTP against JCVI internal non-identical protein database for protein similarity, SignalP for signal peptide prediction, TargetP to determine protein final destination, TMHMM for transmembrane domain prediction [100], and Pfam2go to transfer GO terms from Pfam hits that have been 
curated. An illustration of the JCVI Eukaryotic Annotation Pipeline (JEAP) components is shown in Additional file 1. All evidence was evaluated and ranked according to a priority rules hierarchy to give a final functional assignment reflected in a product name.

In addition to the above analyses, we performed protein clustering within the predicted proteome using a domainbased approach [101]. With this approach, proteins are organized into protein families to facilitate functional annotation, visualizing relationships between proteins and to allow annotation by assessment of related genes as a group, and rapidly identify genes of interest. This clustering method produces groups of proteins sharing protein domains conserved across the proteome, and consequently, related biochemical function.

For functional annotation curation we used Manatee [102]. Predicted E. invadens proteins were grouped on the basis of shared Pfam/TIGRfam domains and potential novel domains. To identify known and novel domains in E. invadens, the proteome was searched against Pfam and TIGRfam HMM profiles using HMMER3 [103]. For new domains, all sequences with known domain hits above the domain trusted cutoff were removed from the predicted protein sequences and the remaining peptide sequences were subject to all versus all BLASTP searches and subsequent clustering. Clustering of similar peptide sequences was done by linkage between any two peptide sequences having at least $30 \%$ identity over a minimum span of 50 amino acids, and an e-value $<0.001$. The Jaccard coefficient of community Ja,b was calculated for each linked pair of peptide sequences $a$ and $b$, as follows: $\mathrm{Ja}, \mathrm{b}=[($ Number of distinct accessions matching $\mathrm{a}$ and $\mathrm{b}$, including $(\mathrm{a}, \mathrm{b})) /($ Number of distinct accessions matching either $\mathrm{a}$ or $\mathrm{b}$ )]. The Jaccard coefficient Ja,b (also called the link score) represents the similarity between the two peptides $a$ and $b$. The associations between peptides with a link score above 0.6 were used to generate single linkage clusters and aligned using ClustalW [104] and then used to develop conserved protein domains not present in the Pfam and TIGRfam databases. Any E. invadensspecific domain alignments containing five or more members were considered true domains for the purpose of clustering protein families. The peptides in the alignments were searched back against the E. invadens proteome to find additional members that may have been excluded during earlier stages due to the parameters employed. Full-length protein sequences were then grouped on the basis of the presence of Pfam/TIGRfam domains and potential novel domains. Proteins with exactly the same domain composition were then classified into putative domain-based protein families. All genome sequence and annotations have been deposited in GenBank under the Whole Genome Shotgun Assembly accession number [AANW00000000], Bioproject accession PRJNA12926 ID: 12926. Latest GenBank Assembly (EIA2v2) ID is GCA_000168215.2.

\section{In vitro culture of $E$. invadens and induction of stage conversion}

E. invadens strain IP-1 [5] was maintained in LYI-S-2 [105] at $25^{\circ} \mathrm{C}$. Encystation was induced by incubation in $47 \%$ LYI-LG, similar to previous methods [42], for $8 \mathrm{~h}$, $24 \mathrm{~h}, 48 \mathrm{~h}$ or $72 \mathrm{~h}$. For excystation, $72 \mathrm{~h}$ cysts were preincubated overnight (approximately $16 \mathrm{~h}$ ) in distilled water at $4^{\circ} \mathrm{C}$ to lyse trophozoites, then induced to excyst by incubation in LYI-LG with the $1 \mathrm{mg} / \mathrm{ml}$ bile (Sigma, St. Louis, MO, USA)), $40 \mathrm{mM}$ sodium bicarbonate (Sigma), 1\% glucose and 10\% serum for $2 \mathrm{~h}$ or $8 \mathrm{~h} \mathrm{[11].}$ Encystation efficiency was assayed by treatment for 30 minutes with $0.1 \%$ sarkosyl on ice, which lyses trophozoites, allowing the percentage of mature $(>48 \mathrm{~h})$ cysts in the population to be calculated. For early ( 8 to $24 \mathrm{~h}$ ) time points at which cysts are not sarkosyl resistant a separate tube of parasites, placed into encystation media at the same time, was allowed to complete development and encystation efficiencies calculated. Excystation efficiency was calculated as percentage of sarkosyl-sensitive trophozoites at $24 \mathrm{~h}$ after transfer to excystation media. Nuclear staining was performed using Syto-11 nucleic acid stain (Life Technologies, Foster City, CA, USA) and imaged on a Leica CTR6500 using Leica Application Suite Advanced Fluorescence software.

\section{RNA extraction and preparation of whole transcriptome sequencing libraries}

Two independent biological replicates were generated for each time point for the RNA-Seq libraries; a third biological sample was used to generate RNA for Northern blot analyses. When possible, samples from the same encystation experiment were used for the RNASeq libraries. Sample groupings are as follows: Cyst 8h-1 and Cyst 24h-1; Cyst 48h-1 and Cyst 72h-1; Cyst 8h-2, Cyst 24h-2 and Cyst 48h-2; Cyst 72h-2; Excyst 2h-1 and Excyst 8h-1; Excyst 2h-2 and Excyst 8h-2. At each time point, parasites were harvested by chilling on ice, spun down, and washed once in cold phosphate buffered saline solution, $\mathrm{pH}$ 7.4. Trophozoites, 8 to $24 \mathrm{~h}$ encystation and 2 to $8 \mathrm{~h}$ excystation samples were immediately resuspended in $5 \mathrm{ml}$ RNA isolation lysis buffer (Ambion, Austin TX, USA)). Mature cysts (48 h and $72 \mathrm{~h}$ ) were first treated by incubation for 30 minutes on ice in $0.1 \%$ sarkosyl to remove any trophozoites or immature cysts. All samples were lysed using a French press at $400 \mathrm{psi}$, which lyses $>90 \%$ of cysts (confirmed by visual inspection) without significant shearing of nucleic acids. Following lysis, RNA was isolated using Trizol reagent (Life 
Technologies) following the manufacturer's protocol. Total RNA was checked for quality using an Agilent BioAnalyzer.

For preparation of cDNA, $5 \mu \mathrm{g}$ total RNA was treated with Terminator enzyme (Epicentre, Madison, WI, USA) to degrade uncapped RNAs $\left(60\right.$ minutes at $30^{\circ} \mathrm{C}$ in $20 \mu \mathrm{l}$ total reaction), followed by heat inactivation for 10 minutes at $65^{\circ} \mathrm{C}$. Samples were diluted to $100 \mu \mathrm{l}$ in $1 \times$ DNAse buffer, and treated with DNAseI (Life Technologies) for 20 minutes at room temperature. Samples were purified using the Ribominus cleanup protocol (Life Technologies) and reanalyzed by the BioAnalyzer to determine the level of mRNA enrichment. Firststrand cDNA synthesis, using 30 ng of mRNA-enriched RNA as a template, was performed with a modified version of the SMART protocol (SMART; Clontech, Mountain View, CA, USA; originally described as Capfinder) $[106,107]$. Adaptors containing the rare asymmetrical restriction sites for Sfil were incorporated into the cDNA using a template switching mechanism at the 5' end of the RNA transcript. For SMART PCR amplification of first-strand cDNA, a SMART PCR primer was used to anneal to identical sequence regions on both the 3 ' and 5' adaptors (primers used for first strand synthesis are listed in Additional file 12). Following 20 to 24 cycles of PCR amplification using Advantage Taq (Clontech) according to the manufacturer's instructions, samples were digested with SfiI (New England Biolabs, Ipswich, MA, USA) to remove the majority of adaptor sequences. Samples were purified using a Nucelospin column (Macherey Nagel, Duren, Germany) to remove digested adaptors.

Amplified, double-stranded cDNA was used to prepare $\mathrm{SOLiD}^{\mathrm{TM}}$ fragment libraries according to the manufacturer's protocols (Life Technologies). Briefly, cDNA was fragmented by sonication on a Covaris $\mathrm{S} 2$ sonicator (Covaris Inc., Woburn, MA, USA) and end-repaired in preparation for P1 and P2 adaptor ligation. Adaptors were ligated and the samples size selected and amplified by standard PCR. DNA was bound to SOLiD ${ }^{\mathrm{TM}} \mathrm{P} 1$ beads and amplified by emulsion PCR, followed by enrichment for templated beads. The DNA was 3' modified before deposition on the sequencing slide, ensuring attachment of the beads to the slide. Libraries were sequenced on a SOLiD ${ }^{\mathrm{TM}}$ 4 sequencer (Life Technologies) to produce 50 bp reads.

\section{Mapping of whole transcriptome sequencing libraries to the $E$. invadens genome assembly}

To determine gene expression levels, sequencing libraries made from cDNA representing the E. invadens transcriptome at time points during encystation and excystation were mapped to the E. invadens genome assembly using Bowtie v0.12.7 [43]. Colorspace reads of 50 nucleotides were trimmed to 35 nucleotides (removing one base from the 5' end and 14 from the more error-prone 3' end) and mapped, allowing up to three (colorspace) mismatches against the reference (option ' $-\mathrm{v} 3$ '). Reads mapping to more than one position in the reference genome were not included in the final alignment (option '-m 1'). For additional analyses to detect unannotated and misannotated genes, full-length reads were also mapped using the Tophat v1.3.2 [46]. The reason for these two independent alignments is that Tophat can identify introns (Bowtie cannot) but tends to map fewer reads overall. Tophat detects introns by splitting reads that do not align to the genome at their full length into segments, mapping each segment separately and using this alignment to identify introns. However, for short single-end reads, as in our data, it can map to more junctions if given a set of already predicted splice junctions to confirm. Therefore, a two-step mapping strategy was used. Initial 'unguided' alignments (with no prior predicted splice junctions) were carried out with each library using default parameters (except for specifying minimum and maximum allowed intron sizes of 40 and $4,000 \mathrm{bp}$ ) to define splice junctions. Then, all putative splice junctions were collected together with those predicted by de novo gene calling. Finally, 'guided' alignments were carried out, using these predicted splice junctions, with minimum and maximum allowed intron sizes of $40 \mathrm{bp}$ and 4,000 bp and otherwise default parameters. Sequence and quality files from all 14 samples, and final normalized FPKM for each gene are deposited at the NCBI Gene Expression Omnibus (GEO) under accession number [GSE45132].

\section{Identification and characterization of differentially expressed genes}

Bowtie alignments from all time points were used to generate FPKM values for each gene and identify differentially expressed genes using Cufflinks v2.0.1 [51]. Expression levels were normalized using upper quartile normalization and $P$-values for differential expression adjusted for a FDR of 0.01 . Gene annotations were from the E. invadens genome version 1.3 [108]. A separate Cufflinks analysis was run without a reference annotation to identify potential unannotated genes. Pairwise comparisons between each of the seven time points were performed (Additional file 9). GO terms were retrieved from AmoebaDB [58]. Pfam domain analysis was carried out by searching the Pfam database [109] with protein FASTA files downloaded from AmoebaDB [58].

\section{Defining temporal gene expression profiles}

Gene expression profiles over the course of encystation and excystation were defined using the Short TimeSeries Expression Miner (STEM) [50]. FPKM expression 
values were used to define two time series: encystation $(0 \mathrm{~h}, 8 \mathrm{~h}, 24 \mathrm{~h}, 48 \mathrm{~h}, 72 \mathrm{~h}$ post-encystation) and excystation (72 h cyst, $2 \mathrm{~h}$ and $8 \mathrm{~h}$ post-excystation). Genes with FPKM $=0$ at any time point were filtered out and each gene's expression values were log-normalized to the first time point, $\log _{2}$ (Time point $\mathrm{n} /$ Time point 0 ), to give an individual temporal expression profile. These were clustered into profiles and sets of related profiles as follows. A given number, $x$, of distinct profiles were defined to represent all possible expression profiles over $n$ time points ( 5 for encystation, 3 for excystation) allowing up to a given amount, $y$, of expression change per step. Parameters $x$ and $y$ were set at 50 and 5 (up to $\log _{2}(32)$-fold change per step). Observed gene profiles were assigned to the representative profiles they most closely match. A permutation test (permuting time points) was applied to estimate the expected number of genes assigned to each profile and the observed number of genes assigned is compared to this to identify profiles that are significantly more common than expected by chance. Similar profiles form a cluster of related profiles (color-coded in Additional file 8). GO categories associated with genes were used to test for significant enrichment in profiles and clusters. Significance of GO category enrichment was tested by comparing the number of genes in a profile/cluster of size $s$ associated with a GO-category to numbers obtained by randomly sampling the entire gene set with samples of size $s$. The $P$-value, adjusted for testing multiple GO categories, indicates the number of times a random sample contained as many or more genes associated with the same GO category.

\section{Northern blot analysis}

Total RNA was extracted from independent samples of trophozoites, $24 \mathrm{~h}$ encysting cells, $72 \mathrm{~h}$ cysts and $8 \mathrm{~h}$ excysting cells. Total RNA $(20 \mu \mathrm{g})$ from each was run on a $1 \%$ denaturing agarose gel, transferred to nitrocellulose, and hybridized overnight at $68^{\circ} \mathrm{C}$ with a PCR generated probe labeled with $\left[\alpha-{ }^{32} \mathrm{P}\right]$ dATP to the gene being tested. Primers used for probe generation are listed in Additional file 12.

\section{Phospholipase $\mathrm{D}$ activity and butanol inhibition}

PLD activity was measured using the Amplex Red Phospholipase D kit (Molecular Probes, Eugene, OR, USA). Parasites were harvested as trophozoites or at $2 \mathrm{~h}, 5 \mathrm{~h}$, $10 \mathrm{~h}, 24 \mathrm{~h}$ and $48 \mathrm{~h}$ after transfer to encystation media. Immature cysts ( 2 to $24 \mathrm{~h}$ ) were resuspended in $1 \times$ reaction buffer, with the addition of $1 \times$ complete protease inhibitor (Roche, Basel, Switzerland) and lysed by freeze-thaw in dry-ice ethanol, while $48 \mathrm{~h}$ cysts were pretreated in $0.1 \%$ sarkosyl to remove trophozoites and immature cysts, then lysed by sonication into the reaction buffer. Protein concentrations were determined using a Bradford assay, and the same amount of protein per well (either 20 or $30 \mu \mathrm{g}$ ) was used in each assay. Activity was monitored by fluorescence of the Amplex Red reagent at $585 \mathrm{~nm}$, read on a SpectraMax M5 plate reader (Molecular Devices, Sunnyvale, CA, USA). All values were corrected by subtracting the background signal (determined using a negative (no lysate) control) and normalized within each trial to trophozoite lysate activity. At least four independent trials were performed for each time point. For assays using n- and t-butanol, each was added prior to addition of trophozoite lysate (30 $\mu \mathrm{g}$ total protein) to a final concentration of $0.6 \%$; $\mathrm{n}$ or $\mathrm{t}$ - butanol was also added to the negative controls to measure background. Three independent trials were performed and each assay normalized to an untreated control, to which no alcohol was added. Mean values and \pm standard deviation are shown.

The effect of PLD inhibition on encystation was measured by addition of sterile $0.6 \% \mathrm{n}$ - or t-butanol (SigmaAldrich, St Louis, MO, USA) to the encystation media at the initiation of encystation. Encystation was assayed by parasite survival in $0.1 \%$ sarkosyl at $48 \mathrm{~h}$ as previously described, and normalized within each trial to the untreated sample. Three independent trials were performed. Mean values and \pm standard deviation are shown. $P$-value was calculated using Student's $t$-test.

\section{Additional material}

Additional File 1: Flowchart illustrating the JCVI Eukaryotic Annotation Pipeline (JEAP). The flowchart illustrates the steps and software used in eukaryotic genome annotation and gene family assignment that were applied to the $E$. invadens genome assembly.

Additional File 2: Putative multi-gene families (of two or more genes) in the genome of $E$. invadens. Membership of a multi-gene family was defined by sharing the same set of functional protein domains with other genes, rather than by sequence similarity. All genes in the genome are listed, along with membership (or not) of a multigene family. In addition, the BLASTP best hit and reciprocal best hit in $E$. histolytica are shown.

Additional File 3: Mapping statistics for all sequence libraries. Tables recording the total number of reads in each replicate transcriptome library and the total number and percentage of reads aligned to the reference genome sequence. For differential gene expression analysis, Bowtie alignments were of $35 \mathrm{bp}$ reads, allowing up to three

mismatches and only retaining uniquely mapped reads (reads that did not align equally well to more than one genome region). For genome annotation-based analyses, Tophat alignments of combined libraries at each time point were of $50 \mathrm{bp}$ reads, using default parameters. The number of introns identified by each alignment was also recorded.

Additional File 4: Read counts, normalized gene expression levels, temporal expression profiles and significant differential expression versus baseline expression for all 11,549 loci. Table showing expression data for 11,549 annotated $E$. invadens genes. For each gene, the gene ID, product description and genomic location are shown, along with read counts in each gene for each sample, normalized gene expression levels (fragments per kilobase per million mapped reads (FPKM)), lower and upper bounds of the $95 \%$ confidence interval ('FPKM_conf_low' and 'FPKM_conf_high') for each time point, temporal 
gene expression profiles (profile IDs relate to profiles shown in Additiona file 8) and significantly differentially expressed genes compared to expression in trophozoites or $72 \mathrm{~h}$ cysts (for encystation and excystation, respectively).

Additional File 5: Correlation of read count values per gene among replicates taken at the same time point. Scatter plots of nonnormalized read counts per gene for pairs of replicate libraries per time point. Axes are log-scaled for display purposes.

Additional File 6: Results of BLAST search of the Pfam database using translated unannotated transcripts. Table showing the results of searching translated open reading frames of putative transcripts that do not overlap annotated genes against the Pfam database to identify unannotated protein coding genes/pseudogenes.

Additional File 7: Validation of annotated introns by transcriptome mapping. Table recording the status of all 5,894 annotated introns. Predicted introns validated by transcriptome mapping, as well as those where only the $5^{\prime}$ or $3^{\prime}$ end were validated, are shown. In addition to this, reads mapped entirely within an intron are counted to infer incorrect introns (or incompletely spliced introns).

\section{Additional File 8: Temporal gene expression profiles during} encystation and excystation. Expression profiles during encystation and excystation, estimated by the short time course expression miner (STEM) software. Black lines show representative profiles and red lines indicate individual genes assigned to each profile. Each profile is numbered at the top right (these profile numbers are used in Additional file 4) and a $P$-value indicating the significance of gene enrichment (more genes assigned to profile than expected by chance) is shown at the bottom left. Clusters of similar profiles are indicated by colored shading.

Additional File 9: Results of differential gene expressed analysis for all possible pairwise comparisons. Genes significantly differentially regulated (FDR <0.01) by Cuffdiff for each of the 42 pairwise

comparisons among time points. For each gene, gene ID, locus position, sample 1 name, sample 2 name, sample 1 FPKM, sample 2 FPKM, log fold change (log2(FPKM_2/FPKM_1)), test statistic, uncorrected $P$-value and corrected $P$-value (for FDR $<0.01$ ) are shown.

Additional File 10: Complete results of Pfam and GO term analysis. Worksheet 1 contains all Pfam domains that were significantly $(P<0.05)$ enriched in genes up or down regulated at $8 \mathrm{~h}, 24 \mathrm{~h}$ and $72 \mathrm{~h}$ postencystation, at $2 \mathrm{~h}$ post-excystation. Pfam accession number, Pfam symbol, a brief description of the domain, total numbers for each Pfam domain in the $E$. invadens genome, numbers of each domain in the regulated genes, and the $P$-value for enrichment are shown. Worksheet 2 contains all GO terms that were significantly $(P<0.05)$ enriched in genes up or down regulated at $8 \mathrm{~h}, 24 \mathrm{~h}$ and $72 \mathrm{~h}$ post-encystation, and at $2 \mathrm{~h}$ post-excystation. GO accession number, a brief description, total numbers of genes in each category in the $E$. invadens genome, number of genes in each category among the regulated genes, and the $P$-value for enrichment are shown.

Additional File 11: FPKMs of genes related to meiosis. Expression of all meiosis-related genes during encystation and excystation. Gene ID, description and FPKM values for each time point are shown for both meiosis-specific and meiosis-associated genes.

Additional File 12: Sequences of all primers used in this study Sequences for all primers used in this study. (A) Primers used to generate PCR probes used in Northern blotting. For each primer, ID of the targeted gene, primer orientation and sequence are shown. (B) Primers used in cDNA first strand synthesis. Primer name and sequence are shown

\section{Abbreviations}

bp: base pair; FDR: false discovery rate; FPKM: fragments per kilobase per million mapped reads; GO: Gene Ontology; HMM: hidden Markov model; JCVI: J Craig Venter Institute; PCR: polymerase chain reaction; PLD: phospholipase D; RNAi: RNA interference; RNA-Seq: RNA-Sequencing.

\section{Competing interests}

The authors declare that they have no competing interests.

\section{Authors' contributions}

Genome assembly and annotation: HL, EC, NH. Cell culture, RNA extraction, and verification of differential expression data: GE. Transcriptome library preparation and sequencing: DW. Mapping and sequence analysis of transcriptome data: GE, GW. Wrote the manuscript: GE, GW, US, NH. All authors read and approved the final manuscript.

\section{Acknowledgements}

We thank all members of the Singh and Hall labs for invaluable input. We acknowledge Jason Miller, JCVI for the assembly effort. We are indebted to AC Matin for use of the French press. GE and US were supported by grants Al094887 and Al088042 from the NIAID. NH, GW, and DW were supported by project grants from the Wellcome Trust and the UK Medical Research Council (ref. MR/K002279/1). EC and HL were supported by federal funds from the National Institute of Allergy and Infectious Diseases, National Institutes of Health, Department of Health and Human Services under contract numbers N01-Al-33071 and HHSN266200400038C. The funders had no role in study design, data collection and analysis, decision to publish, or preparation of the manuscript.

\section{Authors' details}

'Division of Infectious Diseases, Department of Internal Medicine, Stanford University, Stanford, California, 94305, USA. ${ }^{2}$ Institute of Integrative Biology, University of Liverpool, Crown Street, Liverpool, UK. ${ }^{3}$ J Craig Venter Institute, Rockville, Maryland, L697ZB USA. ${ }^{4}$ Faculty of Science, King Abdulaziz University, Jeddah, 21589, SA. ${ }^{5}$ Department of Microbiology and Immunology, Stanford University, Stanford, California, 94305, USA.

Received: 5 April 2013 Revised: 1 July 2013 Accepted: 26 July 2013 Published: 26 July 2013

\section{References}

1. Haque R, Huston CD, Hughes M, Houpt E, Petri WA Jr: Amebiasis. N Engl J Med 2003, 348:1565-1573.

2. Petri WA Jr, Singh U: Diagnosis and management of amebiasis. Clin Infect Dis 1999, 29:1117-1125.

3. Ali IK, Haque R, Siddique A, Kabir M, Sherman NE, Gray SA, Cangelosi GA, Petri WA Jr: Proteomic analysis of the cyst stage of Entamoeba histolytica. PLoS Negl Trop Dis 2012, 6:e1643.

4. Walsh JA: Problems in recognition and diagnosis of amebiasis: estimation of the global magnitude of morbidity and mortality. Rev Infect Dis 1986, 8:228-238.

5. Meerovitch E: A new host of Entamoeba invadens Rodhain, 1934. Can J Zool 1958, 36:423-427.

6. Eichinger D: Encystation in parasitic protozoa. Curr Opin Microbiol 2001, 4:421-426.

7. Eichinger D: Encystation of entamoeba parasites. Bioessays 1997, 19:633-639.

8. Singh U, Ehrenkaufer GM: Recent insights into Entamoeba development: identification of transcriptional networks associated with stage conversion. Int J Parasitol 2009, 39:41-47.

9. Ehrenkaufer GM, Haque R, Hackney JA, Eichinger DJ, Singh U: Identification of developmentally regulated genes in Entamoeba histolytica: insights into mechanisms of stage conversion in a protozoan parasite. Cell Microbiol 2007, 9:1426-1444

10. Balamuth W: Biological studies on Entamoeba histolytica. III. Induced encystation in several mediums, including an account of a new procedure. J Infect Dis 1951, 88:230-236.

11. Mitra BN, Pradel G, Frevert U, Eichinger D: Compounds of the upper gastrointestinal tract induce rapid and efficient excystation of Entamoeba invadens. Int J Parasitol 2010, 40:751-760.

12. Samuelson J, Robbins P: A simple fibril and lectin model for cyst walls of Entamoeba and perhaps Giardia. Trends Parasitol 2011, 27:17-22.

13. Makioka A, Kumagai M, Hiranuka K, Kobayashi S, Takeuchi T: Different structure and mRNA expression of Entamoeba invadens chitinases in the encystation and excystation. Parasitol Res 2011, 109:417-423. 
14. Makioka A, Kumagai M, Ohtomo H, Kobayashi S, Takeuchi T: Entamoeba invadens: protein kinase $\mathrm{C}$ inhibitors block the growth and encystation. Exp Parasitol 2000, 95:288-290.

15. Makioka A, Kumagai M, Ohtomo H, Kobayashi S, Takeuchi T: Involvement of signaling through protein kinase $C$ and phosphatidylinositol 3-kinase in the encystation of Entamoeba invadens. Arch Med Res 2000, 31(Suppl 4):185-186.

16. Makioka A, Kumagai M, Ohtomo H, Kobayashi S, Takeuchi T: Effect of cytochalasin D on the growth, encystation, and multinucleation of Entamoeba invadens. Parasitol Res 2000, 86:599-602.

17. Singh N, Ojha S, Bhattacharya A, Bhattacharya S: Stable transfection and continuous expression of heterologous genes in Entamoeba invadens. Mol Biochem Parasitol 2012, 184:9-12.

18. Ehrenkaufer $\mathrm{GM}$, Singh U: Transient and stable transfection in the protozoan parasite Entamoeba invadens. Mol Biochem Parasitol 2012, 184:59-62.

19. Ben Mamoun C, Gluzman IY, Hott C, MacMillan SK, Amarakone AS, Anderson DL, Carlton JM, Dame JB, Chakrabarti D, Martin RK, Brownstein BH, Goldberg DE: Co-ordinated programme of gene expression during asexual intraerythrocytic development of the human malaria parasite Plasmodium falciparum revealed by microarray analysis. Mol Microbiol 2001, 39:26-36.

20. Cleary MD, Singh U, Blader IJ, Brewer JL, Boothroyd JC: Toxoplasma gondii asexual development: identification of developmentally regulated genes and distinct patterns of gene expression. Eukaryot Cell 2002, 1:329-340.

21. Faghiri Z, Widmer G: A comparison of the Giardia lamblia trophozoite and cyst transcriptome using microarrays. BMC Microbiol 2011, 11:91.

22. Wang Z, Gerstein M, Snyder M: RNA-Seq: a revolutionary tool for transcriptomics. Nat Rev Genet 2009, 10:57-63.

23. Myers EW, Sutton GG, Delcher AL, Dew IM, Fasulo DP, Flanigan MJ, Kravitz SA, Mobarry CM, Reinert KH, Remington KA, Anson EL, Bolanos RA, Chou HH, Jordan CM, Halpern AL, Lonardi S, Beasley EM, Brandon RC, Chen L, Dunn PJ, Lai Z, Liang Y, Nusskern DR, Zhan M, Zhang Q, Zheng X, Rubin GM, Adams MD, Venter JC: A whole-genome assembly of Drosophila. Science 2000, 287:2196-2204.

24. Lorenzi H, Thiagarajan M, Haas B, Wortman J, Hall N, Caler E: Genome wide survey, discovery and evolution of repetitive elements in three Entamoeba species. BMC Genomics 2008, 9:595.

25. Raffaele $\mathrm{S}$, Kamoun S: Genome evolution in filamentous plant pathogens: why bigger can be better. Nat Rev Microbiol 2012, 10:417-430.

26. Zhang H, Ehrenkaufer GM, Pompey JM, Hackney JA, Singh U: Small RNAs with 5 '-polyphosphate termini associate with a Piwi-related protein and regulate gene expression in the single-celled eukaryote Entamoeba histolytica. PLoS Pathog 2008, 4:e1000219.

27. Pearson RJ, Morf $L$, Singh U: Regulation of $\mathrm{H} 2 \mathrm{O} 2$ stress responsive genes through a novel transcription factor in the protozoan pathogen Entamoeba histolytica. J Biol Chem 2012, 288:4462-4474.

28. Meneses E, Cardenas H, Zarate S, Brieba LG, Orozco E, Lopez-Camarillo C, Azuara-Liceaga E: The R2R3 Myb protein family in Entamoeba histolytica. Gene 2010, 455:32-42.

29. Ehrenkaufer GM, Hackney JA, Singh U: A developmentally regulated Myb domain protein regulates expression of a subset of stage-specific genes in Entamoeba histolytica. Cell Microbiol 2009, 11:898-910.

30. Agrawal N, Dasaradhi PV, Mohmmed A, Malhotra P, Bhatnagar RK, Mukherjee SK: RNA interference: biology, mechanism, and applications. Microbiol Mol Biol Rev 2003, 67:657-685.

31. Zhang $H$, Ehrenkaufer GM, Hall N, Singh U: Small RNA pyrosequencing in the protozoan parasite Entamoeba histolytica reveals strain-specific small RNAs that target virulence genes. BMC Genomics 2013, 14:53.

32. Zhang $H$, Alramini $H$, Tran $V$, Singh U: Nucleus-localized antisense small RNAs with 5'-polyphosphate termini regulate long term transcriptional gene silencing in Entamoeba histolytica G3 strain. J Biol Chem 2011, 286:44467-44479.

33. Hock J, Meister G: The Argonaute protein family. Genome Biol 2008, 9:210.

34. Oh $\mathbb{H}$, Reddy EP: The myb gene family in cell growth, differentiation and apoptosis. Oncogene 1999, 18:3017-3033.

35. Jin $H$, Martin C: Multifunctionality and diversity within the plant MYBgene family. Plant Mol Biol 1999, 41:577-585.

36. Sun CH, Palm D, McArthur AG, Svard SG, Gillin FD: A novel Myb-related protein involved in transcriptional activation of encystation genes in Giardia lamblia. Mol Microbiol 2002, 46:971-984.
37. Clark CG, Alsmark UC, Tazreiter M, Saito-Nakano Y, Ali V, Marion S, Weber C, Mukherjee C, Bruchhaus I, Tannich E, Leippe M, Sicheritz-Ponten T, Foster PG, Samuelson J, Noël CJ, Hirt RP, Embley TM, Gilchrist CA, Mann BJ, Singh U, Ackers JP, Bhattacharya S, Bhattacharya A, Lohia A, Guillén N, Duchêne M, Nozaki T, Hall N: Structure and content of the Entamoeba histolytica genome. Adv Parasitol 2007, 65:51-190.

38. Gilchrist CA, Houpt E, Trapaidze N, Fei Z, Crasta O, Asgharpour A, Evans C, Martino-Catt S, Baba DJ, Stroup S, Hamano S, Ehrenkaufer G, Okada M, Singh U, Nozaki T, Mann BJ, Petri WA Jr: Impact of intestinal colonization and invasion on the Entamoeba histolytica transcriptome. Mol Biochem Parasitol 2006, 147:163-176.

39. Santi-Rocca J, Weber C, Guigon G, Sismeiro O, Coppee JY, Guillen N: The lysine- and glutamic acid-rich protein KERP1 plays a role in Entamoeba histolytica liver abscess pathogenesis. Cell Microbiol 2008, 10:202-217.

40. Feller A, Machemer K, Braun EL, Grotewold E: Evolutionary and comparative analysis of MYB and bHLH plant transcription factors. Plant J 2011, 66:94-116.

41. Fukuzawa M, Zhukovskaya NV, Yamada Y, Araki T, Williams JG: Regulation of Dictyostelium prestalk-specific gene expression by a SHAQKY family MYB transcription factor. Development 2006, 133:1715-1724.

42. Sanchez $L$, Enea $V$, Eichinger $D$ : Identification of a developmentally regulated transcript expressed during encystation of Entamoeba invadens. Mol Biochem Parasitol 1994, 67:125-135.

43. Langmead B, Trapnell C, Pop M, Salzberg SL: Ultrafast and memoryefficient alignment of short DNA sequences to the human genome. Genome Biol 2009, 10:R25.

44. Suzuki S, Ono N, Furusawa C, Ying BW, Yomo T: Comparison of sequence reads obtained from three next-generation sequencing platforms. PLOS One 2011, 6:e19534.

45. Oshlack A, Robinson MD, Young MD: From RNA-seq reads to differential expression results. Genome Biol 2010, 11:220.

46. Trapnell C, Pachter L, Salzberg SL: TopHat: discovering splice junctions with RNA-Seq. Bioinformatics 2009, 25:1105-1111.

47. Pfam database. [http://pfam.sanger.acuk/]

48. Davis CA, Brown MP, Singh U: Functional characterization of spliceosomal introns and identification of U2, U4, and U5 snRNAs in the deepbranching eukaryote Entamoeba histolytica. Eukaryot Cell 2007, 6:940-948.

49. Hon CC, Weber C, Sismeiro O, Proux C, Koutero M, Deloger M, Das S, Agrahari M, Dillies MA, Jagla B, Coppee JY, Bhattacharya A, Guillen N: Quantification of stochastic noise of splicing and polyadenylation in Entamoeba histolytica. Nucleic Acids Res 2012, 41:1936-1952.

50. Ernst J, Bar-Joseph Z: STEM: a tool for the analysis of short time series gene expression data. BMC Bioinformatics 2006, 7:191.

51. Trapnell C, Williams BA, Pertea G, Mortazavi A, Kwan G, van Baren MJ, Salzberg SL, Wold BJ, Pachter L: Transcript assembly and quantification by RNA-Seq reveals unannotated transcripts and isoform switching during cell differentiation. Nat Biotechnol 2010, 28:511-515.

52. Alcolea PJ, Alonso A, Gomez MJ, Moreno I, Dominguez M, Parro V, Larraga V: Transcriptomics throughout the life cycle of Leishmania infantum: high down-regulation rate in the amastigote stage. Int $\mathrm{J}$ Parasitol 2010, 40:1497-1516.

53. Morf L, Spycher C, Rehrauer H, Fournier CA, Morrison HG, Hehl AB: The transcriptional response to encystation stimuli in Giardia lamblia is restricted to a small set of genes. Eukaryot Cell 2010, 9:1566-1576.

54. Chatterjee A, Ghosh SK, Jang K, Bullitt E, Moore L, Robbins PW, Samuelson J: Evidence for a "wattle and daub" model of the cyst wall of entamoeba. PLoS Pathog 2009, 5:e1000498.

55. Katz U, Ankri S, Stolarsky T, Nuchamowitz Y, Mirelman D: Entamoeba histolytica expressing a dominant negative $\mathrm{N}$-truncated light subunit of its gal-lectin are less virulent. Mol Biol Cell 2002, 13:4256-4265.

56. Jeelani G, Sato D, Husain A, Escueta-de Cadiz A, Sugimoto M, Soga T, Suematsu M, Nozaki T: Metabolic profiling of the protozoan parasite Entamoeba invadens revealed activation of unpredicted pathway during encystation. PLoS One 2012, 7:e37740.

57. Gilchrist CA, Petri WA Jr: Using differential gene expression to study Entamoeba histolytica pathogenesis. Trends Parasitol 2009, 25:124-131.

58. AmoebaDB. [http://amoebadb.org/amoeba/].

59. Gene Ontology. [http://www.geneontology.org/].

60. Coppi A, Merali S, Eichinger D: The enteric parasite Entamoeba uses an autocrine catecholamine system during differentiation into the infectious cyst stage. J Biol Chem 2002, 277:8083-8090. 
61. Kotter K, Klein J: Ethanol inhibits astroglial cell proliferation by disruption of phospholipase D-mediated signaling. J Neurochem 1999, 73:2517-2523.

62. Walker R, Gissot M, Croken MM, Huot L, Hot D, Kim K, Tomavo S: The Toxoplasma nuclear factor TgAP2XI-4 controls bradyzoite gene expression and cyst formation. Mol Microbiol 2013, 87:641-655.

63. Wang YT, Pan YJ, Cho CC, Lin BC, Su LH, Huang YC, Sun CH: A novel paxlike protein involved in transcriptional activation of cyst wall protein genes in Giardia lamblia. J Biol Chem 2010, 285:32213-32226.

64. Yuda M, Iwanaga S, Shigenobu S, Kato T, Kaneko I: Transcription factor AP2-Sp and its target genes in malarial sporozoites. Mol Microbiol 2010, 75:854-863.

65. Anderson MZ, Brewer J, Singh U, Boothroyd JC: A pseudouridine synthase homologue is critical to cellular differentiation in Toxoplasma gondii. Eukaryot Cell 2009, 8:398-409.

66. Davis PH, Zhang X, Guo J, Townsend RR, Stanley SL Jr: Comparative proteomic analysis of two Entamoeba histolytica strains with different virulence phenotypes identifies peroxiredoxin as an important component of amoebic virulence. Mol Microbiol 2006, 61:1523-1532.

67. Baxt LA, Rastew E, Bracha R, Mirelman D, Singh U: Downregulation of an Entamoeba histolytica rhomboid protease reveals roles in regulating parasite adhesion and phagocytosis. Eukaryot Cell 2010, 9:1283-1293.

68. MacFarlane RC, Singh U: Identification of an Entamoeba histolytica serinethreonine-, and isoleucine-rich protein with roles in adhesion and cytotoxicity. Eukaryot Cell 2007, 6:2139-2146.

69. Barker DC, Svihla G: Localization of cytoplasmic nucleic acid during growth and encystment of Entamoeba invadens. J Cell Biol 1964, 20:389-398.

70. Singh N, Bhattacharya S, Paul J: Entamoeba invadens: dynamics of DNA synthesis during differentiation from trophozoite to cyst. Exp Parasitol 2011, 127:329-333.

71. Makioka A, Kumagai M, Kobayashi S, Takeuchi T: Entamoeba invadens: cysteine protease inhibitors block excystation and metacystic development. Exp Parasitol 2005, 109:27-32.

72. Gibson W, Bailey M: Genetic exchange in Trypanosoma brucei: evidence for meiosis from analysis of a cross between drug-resistant transformants. Mol Biochem Parasitol 1994, 64:241-252.

73. Malik SB, Pightling AW, Stefaniak LM, Schurko AM, Logsdon JM Jr: An expanded inventory of conserved meiotic genes provides evidence for sex in Trichomonas vaginalis. PLoS One 2008, 3:e2879.

74. Poxleitner MK, Carpenter ML, Mancuso JJ, Wang CJ, Dawson SC, Cande WZ: Evidence for karyogamy and exchange of genetic material in the binucleate intestinal parasite Giardia intestinalis. Science 2008, 319:1530-1533.

75. Weedall GD, Clark CG, Koldkjaer P, Kay S, Bruchhaus I, Tannich E, Paterson S, Hall N: Genomic diversity of the human intestinal parasite Entamoeba histolytica. Genome Biol 2012, 13:R38.

76. Orozco E, Solis FJ, Dominguez J, Chavez B, Hernandez F: Entamoeba histolytica: cell cycle and nuclear division. Exp Parasitol 1988, 67:85-95.

77. Tsubouchi H, Roeder GS: The Mnd1 protein forms a complex with hop2 to promote homologous chromosome pairing and meiotic doublestrand break repair. Mol Cell Biol 2002, 22:3078-3088

78. Bishop DK, Park D, Xu L, Kleckner N: DMC1: a meiosis-specific yeast homolog of $E$. coli recA required for recombination, synaptonemal complex formation, and cell cycle progression. Cell 1992, 69:439-456.

79. Borts RH, Chambers SR, Abdullah MF: The many faces of mismatch repair in meiosis. Mutat Res 2000, 451:129-150.

80. Cockcroft S: Signalling roles of mammalian phospholipase D1 and D2. Cell Mol Life Sci 2001, 58:1674-1687.

81. Jenkins GM, Frohman MA: Phospholipase D: a lipid centric review. Cell Mol Life Sci 2005, 62:2305-2316.

82. Morris AJ, Frohman MA, Engebrecht J: Measurement of phospholipase D activity. Anal Biochem 1997, 252:1-9.

83. Latijnhouwers M, Munnik T, Govers F: Phospholipase D in Phytophthora infestans and its role in zoospore encystment. Mol Plant Microbe Interact 2002, 15:939-946.

84. Chen Y, Rodrick V, Yan Y, Brazill D: PldB, a putative phospholipase D homologue in Dictyostelium discoideum mediates quorum sensing during development. Eukaryot Cell 2005, 4:694-702.

85. Becker KP, Hannun YA: Protein kinase $C$ and phospholipase D: intimate interactions in intracellular signaling. Cell Mol Life Sci 2005, 62:1448-1461.
86. Liscovitch M, Czarny M, Fiucci G, Tang X: Phospholipase D: molecular and cell biology of a novel gene family. Biochem J 2000, 345:401-415.

87. Aguilar-Diaz H, Carrero JC, Arguello-Garcia R, Laclette JP, Morales-Montor J: Cyst and encystment in protozoan parasites: optimal targets for new life-cycle interrupting strategies? Trends Parasitol 2011, 27:450-458.

88. Lauwaet T, Davids BJ, Reiner DS, Gillin FD: Encystation of Giardia lamblia: a model for other parasites. Curr Opin Microbiol 2007, 10:554-559.

89. Paget TA, Macechko PT, Jarroll EL: Metabolic changes in Giardia intestinalis during differentiation. J Parasitol 1998, 84:222-226.

90. Roberts M, Hunt BR, Yorke JA, Bolanos RA, Delcher AL: A preprocessor for shotgun assembly of large genomes. J Comput Biol 2004, 11:734-752.

91. Lowe TM, Eddy SR: tRNAscan-SE: a program for improved detection of transfer RNA genes in genomic sequence. Nucleic Acids Res 1997, 25:955-964.

92. Allen JE, Majoros WH, Pertea M, Salzberg SL: JIGSAW, GeneZilla, and GlimmerHMM: puzzling out the features of human genes in the ENCODE regions. Genome Biol 2006, 7(Suppl 1):1-13.

93. Stanke M, Schoffmann O, Morgenstern B, Waack S: Gene prediction in eukaryotes with a generalized hidden Markov model that uses hints from external sources. BMC Bioinformatics 2006, 7:62.

94. Flicek P, Keibler E, Hu P, Korf I, Brent MR: Leveraging the mouse genome for gene prediction in human: from whole-genome shotgun reads to a global synteny map. Genome Res 2003, 13:46-54.

95. Huang X, Adams MD, Zhou H, Kerlavage AR: A tool for analyzing and annotating genomic sequences. Genomics 1997, 46:37-45.

96. Haas BJ, Salzberg SL, Zhu W, Pertea M, Allen JE, Orvis J, White O, Buell CR, Wortman JR: Automated eukaryotic gene structure annotation using EVidenceModeler and the Program to Assemble Spliced Alignments. Genome Biol 2008, 9:R7.

97. Claudel-Renard C, Chevalet C, Faraut T, Kahn D: Enzyme-specific profiles for genome annotation: PRIAM. Nucleic Acids Res 2003, 31:6633-6639.

98. Punta M, Coggill PC, Eberhardt RY, Mistry J, Tate J, Boursnell C, Pang N, Forslund K, Ceric G, Clements J, Heger A, Holm L, Sonnhammer EL, Eddy SR, Bateman A, Finn RD: The Pfam protein families database. Nucleic Acids Res 2012, 40(Database):290-301.

99. Haft DH, Selengut JD, White O: The TIGRFAMs database of protein families. Nucleic Acids Res 2003, 31:371-373.

100. Emanuelsson O, Brunak S, von Heijne G, Nielsen H: Locating proteins in the cell using TargetP, SignalP and related tools. Nat Protoc 2007, 2:953-971.

101. Lin H, Ouyang S, Egan A, Nobuta K, Haas BJ, Zhu W, Gu X, Silva JC, Meyers BC, Buell CR: Characterization of paralogous protein families in rice. BMC Plant Biol 2008, 8:18.

102. Manatee. [http://manatee.sourceforge.net/].

103. Eddy SR: Accelerated Profile HMM Searches. PLoS Comput Biol 2011, 7: e1002195.

104. Thompson JD, Higgins DG, Gibson TJ: CLUSTAL W: improving the sensitivity of progressive multiple sequence alignment through sequence weighting, position-specific gap penalties and weight matrix choice. Nucleic Acids Res 1994, 22:4673-4680.

105. Clark CG, Diamond LS: Methods for cultivation of luminal parasitic protists of clinical importance. Clin Microbiol Rev 2002, 15:329-341.

106. Zhu YY, Machleder EM, Chenchik A, Li R, Siebert PD: Reverse transcriptase template switching: a SMART approach for full-length CDNA library construction. Biotechniques 2001, 30:892-897.

107. Wellenreuther R, Schupp I, Poustka A, Wiemann S: SMART amplification combined with CDNA size fractionation in order to obtain large fulllength clones. BMC Genomics 2004, 5:36.

108. E. invadens genome release 1.3. [http://amoebadb.org/common/ downloads/release-1.3/Einvadens/gff/].

109. Celera assembler. [http://wgs-assembler.sf.net].

doi:10.1186/gb-2013-14-7-r77

Cite this article as: Ehrenkaufer et al:: The genome and transcriptome of the enteric parasite Entamoeba invadens, a model for encystation. Genome Biology 2013 14:R77. 